\title{
Insights Into the Polerovirus-Plant Interactome Revealed by Coimmunoprecipitation and Mass Spectrometry
}

\author{
Stacy L. DeBlasio, ${ }^{1,2}$ Richard Johnson, ${ }^{3}$ Jaclyn Mahoney, ${ }^{1}$ Alexander Karasev, ${ }^{4}$ Stewart M. Gray, ${ }^{5}$ \\ Michael J. MacCoss, ${ }^{3}$ and Michelle Cilia ${ }^{1,2,5}$ \\ ${ }^{1}$ Boyce Thompson Institute for Plant Research, Ithaca, NY 14853, U.S.A.; ${ }^{2}$ United States Department of Agriculture- \\ Agricultural Research Service, Ithaca, NY 14853, U.S.A.; ${ }^{3}$ Department of Genome Sciences, University of Washington, Seattle \\ 98109, U.S.A.; ${ }^{4}$ University of Idaho, Moscow 83844, U.S.A.; ${ }^{5}$ Department of Plant Pathology and Plant-Microbe Biology, Cornell \\ University, Ithaca, NY 14853, U.S.A.
}

Submitted 19 June 2014. Accepted 27 November 2014.

\begin{abstract}
Identification of host proteins interacting with the aphidborne Potato leafroll virus (PLRV) from the genus Polerovirus, family Luteoviridae, is a critical step toward understanding how PLRV and related viruses infect plants. However, the tight spatial distribution of PLRV to phloem tissues poses challenges. A polyclonal antibody raised against purified PLRV virions was used to coimmunoprecipitate virus-host protein complexes from Nicotiana benthamiana tissue inoculated with an infectious PLRV cDNA clone using Agrobacterium tumefaciens. A. tumefaciensmediated delivery of PLRV enabled infection and production of assembled, insect-transmissible virus in most leaf cells, overcoming the dynamic range constraint posed by a systemically infected host. Isolated protein complexes were characterized using high-resolution mass spectrometry and consisted of host proteins interacting directly or indirectly with virions, as well as the nonincorporated readthrough protein (RTP) and three phosphorylated positional isomers of the RTP. A bioinformatics analysis using ClueGO and STRING showed that plant proteins in the PLRV protein interaction network regulate key biochemical processes, including carbon fixation, amino acid biosynthesis, ion transport, protein folding, and trafficking.
\end{abstract}

Plant viruses are obligate, intracellular pathogens that rely on host factors to complete their life cycle. Natural selection has favored viruses to fine-tune host manipulation strategies for their propagation and transmission with a limited amount of genetic material (Maule et al. 2002). Steps in the viral life cycle generally include evasion of plant defenses, genome replication, encapsidation, viral spread via cell-to-cell movement (local and systemic), acquisition, and transmission by a vector species (Caranta et al. 2011). How well or whether a particular species of virus can infect a host cell depends on specific interactions that occur between viral and host proteins that benefit the virus but do not trigger a detrimental immune response (Dodds and Rathjen 2010; Jones and Dangl 2006). Often, these interactions have pathological effects on host

Corresponding author: M. Cilia: E-mail: mlc68@cornell.edu

*The $\boldsymbol{e}$-Xtra $\log$ o stands for "electronic extra" and indicates that five supplementary figures, four supplementary tables, and two links to additional supplementary data are published online.

This article is in the public domain and not copyrightable. It may be freely reprinted with customary crediting of the source. The American Phytopathological Society, 2015. physiology because resources required for normal plant development are redirected to viral reproduction. These effects manifest as disease symptoms that can severely impact agricultural production (Culver and Padmanabhan 2007; Pallas and García 2011).

Transcript and proteomic profiling of plants infected with virus have revealed some insights into the complex nature of the interplay between different classes of viruses and their hosts. Studies have shown that unrelated plant viruses can alter the expression of similar sets of host proteins during a compatible infection (Whitham et al. 2006). These common, molecular signatures include repression of proteins involved in photosynthesis, upregulation of energy metabolism and protein synthesis, alterations in sugar metabolism, modulation of cells walls, and changes in the expression of defense related proteins (Di Carli et al. 2012; Whitham et al. 2006). Yet, unique expression profiles have also been observed for some viruses, demonstrating the specialized relationships that exist between viruses and hosts (Power and Flecker 2003; Rodrigo et al. 2012). Similar to viruses that infect mammalian systems (Calderwood et al. 2007; de Chassey et al. 2008), plant viruses tend to target host proteins that regulate central points within pathways (Garbutt et al. 2014; Mukhtar et al. 2011; Rodrigo et al. 2012). To help ensure their own transmission, plant viruses can also alter the host metabolome to make plants more attractive to insect vectors (Eigenbrode et al. 2002; JiménezMartínez et al. 2004; Mauck et al. 2010).

As instrumental as these expression studies have been in increasing our knowledge about what changes occur during pathogenesis, they do not provide information on the protein interactions regulating infection. Identification of proteinprotein interactions in planta has been a particular challenge because most plant viruses replicate and move within highly specialized cells not amenable to isolation methods used in animal studies (Stewart et al. 2013). The overwhelming majority of key insights into virus-plant protein interactions have been determined using molecular approaches, such as yeasttwo-hybrid or bimolecular fluorescence complementation. These methods have enhanced the field's understanding of the virus life cycle by enabling the discovery of host proteins that directly interact with individual viral proteins (Nagy 2008). However, these techniques are limited to probing binary interactions and are not ideally suited for discovering host proteins that interact with multimeric protein complexes, such as assembled virion or virus replication factories. Nor can they readily enable the characterization of posttranslational modifications (PTMs) that may occur over the course of an infection to regulate viral processes (Cilia et al. 2014I; Ivanov et al. 2003; 
Ribet and Cossart 2010). Studies conducted in mammalian systems show that virus-host interactions do not occur as single events but as part of a dynamic interaction landscape involving multiple forms of virus and viral proteins (Calderwood et al. 2007; de Chassey et al. 2008; Cristea et al. 2006).

Mass spectrometry-based proteomics is emerging as a powerful, high-throughput approach to characterize entire viral

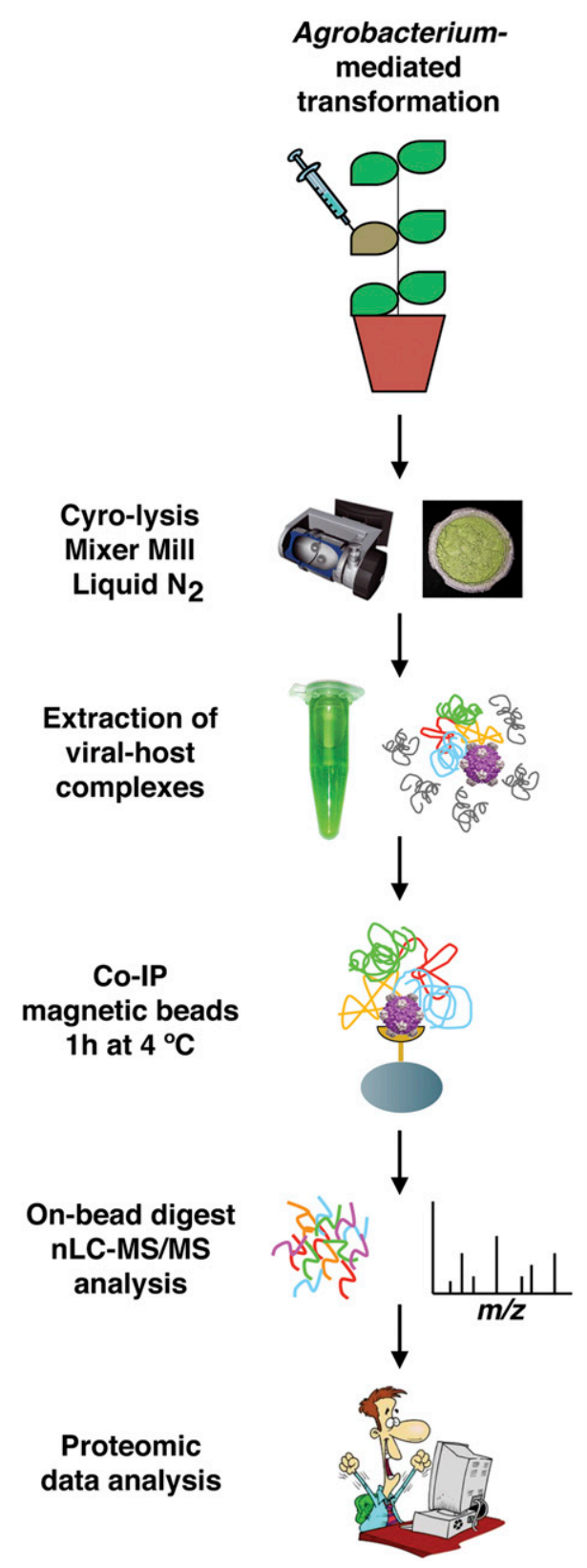

Fig. 1. Schematic of the coimmunoprecipitation (co-IP) workflow for isolating host-virus protein complexes from plant tissue infected with PLRV. Nicotiana benthamiana was infected with PLRV by Agrobacterium-mediated inoculation. Leaf tissue was cryogenically lysed using a mixer mill, and protein complexes were gently extracted in a HEPES-based lysis buffer with a mild detergent. Host-virus complexes were rapidly coimmunoprecipitated using antibody-coated, magnetic beads and digested into peptides for mass spectrometry. Peptides were separated by nanoscale, reverse-phase liquid chromatography and analyzed by high-resolution tandem mass spectrometry (nLC-MS/MS). Resulting peptide spectra were searched against an in-house protein database generated from the $N$. benthamiana draft genome and luteovirid protein sequences for protein identification. The proteomic software programs Scaffold and SAINT (Choi et al. 2011, 2012) were used for label-free quantification of tandem mass spectra by spectral counting, as described by Pinheiro and associates (2014). interactomes (Miteva et al. 2013), expanding the horizon of our knowledge of virus-plant protein interactions well beyond the capabilities afforded by molecular biology alone. For example, Brizard and associates (2006) used tandem mass spectrometry to characterize 233 host proteins copurifying with Rice yellow mottle virus (RYMV), a single-stranded, positive-sense (ssRNA+) sobemovirus (Opalka et al. 1998). Tandem mass spectrometry methods have also reported host proteins copurifying with poleroviruses (Bencharki et al. 2010; Cilia et al. 2012). Similar to RYMV, poleroviruses are ssRNA+ viruses, which move long distance in plants as icosahedral virions. Host proteins interacting with ssRNA+ plant viruses function in photosynthesis, cell wall metabolism, amino acid or lipid biosynthesis, lipid rafts, carbohydrate metabolism, and plant defense. The method used for RYMV-host protein complex isolation was size exclusion chromatography. In contrast, the polerovirus studies relied on density gradient purification to enrich for virus-plant protein complexes. Density gradient purification of poleroviruses resulted in truncation of the $\mathrm{C}$ terminus of the minor, structural readthrough protein (RTP), a component of the virus capsid (Filichkin et al. 1994; Perry et al. 1998; Wang et al. 1995), and eliminated soluble forms of virus proteins that can also complex with host proteins. Peter and colleagues (2009) demonstrated that phloem retention of the Polerovirus Potato leafroll virus (PLRV) is an active strategy mediated by the C-terminal domain of the RTP in its nonincorporated form. An understanding of the protein interactions occurring with this domain is critical to defining the mechanisms of polerovirus movement. Thus, for PLRV and other poleroviruses, a major improvement on a virus enrichment method for mass spectrometry-based protein interaction studies is required.

PLRV is an ideal virus for mass spectrometry-based studies on protein interactions (Chavez et al. 2012). An infectious clone of PLRV is available and the genomes of at least two host plants, Nicotiana benthamiana and Solanum tuberosum, have been sequenced (Bombarely et al. 2012; The Potato Genome Sequencing Consortium et al. 2011), enabling protein identification using traditional proteomics search engines. The virus genome is small, encoding only eight open reading frames (ORFs), two of which encode the structural capsid proteins. The coat protein (CP) encoded by ORF 3 makes up the majority of the PLRV capsid, with a minor amount substituted by the RTP, which is translated via a readthrough of the CP stop codon (Bahner et al. 1990). The $\mathrm{CP}$ domain of the RTP fits within the icosahedral virion structure, with the $\mathrm{C}$ terminus or readthrough domain projecting outward from the surface (Chavez et al. 2012; Torrance 1992). The CP and RTP exist as multiple forms within plant cells, each with distinct roles during infection (Boissinot et al. 2014; Filichkin et al. 1994; Perry et al. 1998; Lee et al. 2005; Kaplan et al. 2007; Peter et al. 2008, 2009; Boissinot et al. 2014; Wang et al. 1995).

Here, we report a method to enrich for host proteins in complex with PLRV coupled to mass spectrometry and statistical analysis for protein interaction identification. We optimized a coimmunoprecipitation (co-IP) strategy (Fig. 1) to rapidly isolate virus from $N$. benthamiana leaf tissue infiltrated with an infectious cDNA clone of PLRV using Agrobacterium tumefaciens (agro)-mediated delivery (Kaplan et al. 2007; Lee et al. 2005). Using this strategy, we isolated PLRV-host complexes that include the intact form of the RTP, three nonstructural viral proteins, as well as over 1,500 host proteins involved in regulating diverse plant biosynthetic processes, including nutrient availability, trafficking, and cellular homeostasis. Furthermore, we confidently identified isoforms of the RTP that are phosphorylated within the C-terminal domain without prior enrichment for phosphorylated peptides, showing that our method is sensitive enough to detect PTMs that typically appear in cells in substoichiometric ratios. 


\section{RESULTS}

\section{co-IP strategy.}

Rapid solation of PLRV from infected $N$. benthamiana plant tissue was achieved by incubating extracted virus-host complexes for $1 \mathrm{~h}$ with Protein A Dynabeads coated with a PLRVspecific polyclonal antibody ( $\alpha$-PLRV) raised against virions purified from Physalis floridiana. Each step of the co-IP workflow (Fig. 1) was optimized for efficient recovery of the viral proteins based on conditions shown to maintain native virus-host interactions in mammalian systems (Cristea et al. 2006, 2010). Mechanical cryolysis of leaf tissue, lysis buffer composition, length of time used for extraction, and lysate concentration all had effects on the co-IP of PLRV, as determined by levels of viral CP detected. Cryogenic lysis of infected $N$. benthamiana leaf tissue using a mixer mill (Mixer Mill 400; Retsch, Hann, Germany) resulted in near complete cell disruption and a twofold increase in total extracted protein relative to grinding frozen tissue in a mortar and pestle (Supplementary Fig. S1). A 50-mM 4-(2-hydroxyethyl)-1-piperazineethanesulfonic acid (HEPES) (pH 7.4)-based buffer supplemented with $0.4 \%$ Triton X-100 generated higher levels of $\mathrm{CP}$ at an optimal buffering capacity over buffers made with phosphate-buffered saline (PBS), Tris, or Tween (Supplementary Fig. S2). Thus, all subsequent extractions used the 50-mM HEPES-based buffer supplemented with $0.4 \%$ TritonX-100 with an extraction incubation time of $30 \mathrm{~min}$, compared with a longer time of $24 \mathrm{~h}$, which decreased the level of CP with or without the addition of protease inhibitors. During optimization of our co-IP step, we observed that there was an optimal concentration at which the virus or viral structural proteins were immunoprecipitated as opposed to nonspecifically coating beads. A 1:5 dilution of the lysate reduced the amount of CP and RTP nonspecifically binding to Protein A Dynabeads coated with rabbit immunoglobulin $\mathrm{G}$ (IgG) compared with Protein A Dynabeads coated with $\alpha$-PLRV (Supplementary Fig. 3S). Dilution of lysate prior to IP was incorporated into our final workflow.

\section{co-IP of PLRV from infected tissue}

maintains the structural integrity of RTP.

The optimized IP workflow enabled us to detect the PLRV structural proteins CP and RTP by Western blot analysis (Fig. $2 \mathrm{~A}$ ), as well as reproducible differences in the composition of proteins coimmunoprecipitating with or without virus- or PLRV-specific antibodies (Fig. 2B). Coupled to nanoflow, reversephase liquid chromatography and high-resolution tandem mass spectrometric analysis (nLC-MS/MS), the PLRV RTP was detected in tryptic digests of our infected $N$. benthamiana $\alpha$-PLRV IP samples with an average Mascot protein score of 13,632 and an average exponentially modified protein abundant index (emPAI) value of 78.23. Sequence coverage of the RTP, including the CP-derived sequences, was between 73 and 84\%. (Supplementary Fig. S4A). We confidently identified peptides spanning the entire protein, including the C-terminal region that is proteolytically cleaved during protein or virus extraction procedures (Filichkin et al. 1994; Perry et al. 1998; Wang et al. 1995), including the last possible C-tryptic peptide of full-length RTP (Supplementary Fig. S4B). These results support our Western blot analysis showing detection of the full-length RTP in the co-IP experiments (Fig. 2A). This is the first report of a method that can be used to isolate the full-length form of the RTP and, thus, any host proteins in complex with the RTP C terminus that could be involved in regulating phloem-retention.

co-IP of PLRV captures the nonincorporated form of RTP.

The PLRV RTP functions as both a structural component of the virion and a soluble protein that regulates phloem retention
(Peter et al. 2009). To test whether the nonincorporated forms of either the CP or RTP were also coimmunoprecipitated, co-IP reactions were performed from $N$. benthamiana tissue infected with two PLRV mutants, $\triangle \mathrm{CP}$ and GP (Kaplan et al. 2007), that produce only the nonincorporated forms of the RTP or CP, respectively. The $\triangle \mathrm{CP}$ mutant has a defective $\mathrm{CP}$ stop codon resulting in translation of only the RTP and not the CP; therefore, no virions can be assembled. The GP mutant translates a CP containing two alanine substitutions that prevent virion assembly and does not translate RTP. Western analysis of the immunoprecipitate indicated that the nonincorporated form of RTP but not unassembled CP was immunoprecipitated (Fig. 3). These data show that protein complexes immunoprecipitated from tissue infected with wild-type (WT) virus include those that form with both virions and the nonincorporated RTP. Although lower levels of CP were detected in leaf tissue infected with the virion assembly GP mutant compared with WT, it is unlikely that the lower expression level of the GP mutant prevented efficient IP of the nonincorporated $\mathrm{CP}$.
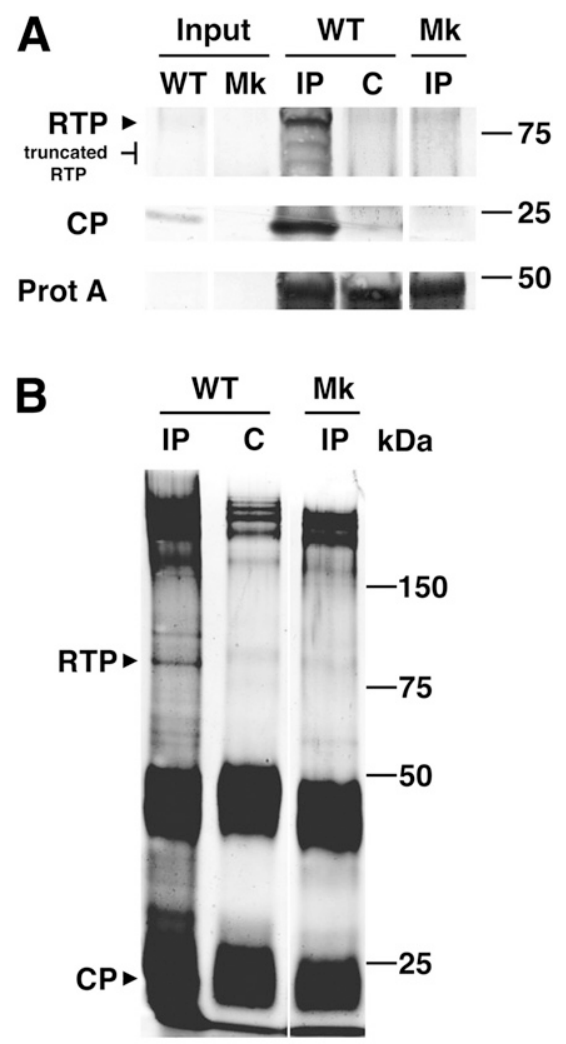

Fig. 2. Immunoprecipitation of PLRV from infected Nicotiana benthamiana leaf tissue enriches for full-length and truncated forms of readthrough protein (RTP) and results in the isolation of virus-host complexes that differ between the wild type (WT) and negative immunoprecipitation (IP) controls. A, Western blot and B, sodium dodecyl sulfate (SDS) polyacrylamide gel electrophoresis (PAGE) analysis of IP eluates from incubation of PLRV-infected N. benthamiana lysate with Protein A-conjugated magnetic beads coated with our custom $\alpha$-PLRV antibody (IP) or rabbit immunoglobulin G (C) for $1 \mathrm{~h}$. Negative controls also included incubation of $\alpha$-PLRV-coated beads with mock-infiltrated $N$. benthamiana (Mk) leaf lysate. A, Levels of PLRV coat protein (CP), RTP, and Protein A were measured in SDS eluates using a commercially available alkaline phosphatase conjugated, PLRV polyclonal antibody (Agdia). Levels of CP and RTP in the input fractions are shown (Input). B, IP eluates were separated by SDS-PAGE and stained with SYPRO Ruby. Protein bands were imaged using a Typhoon Variable Mode Imager (GE Healthcare). 


\section{The RTP is posttranslationally modified.}

Although we did not specifically enrich for peptides containing posttranslational modifications, the co-IP method enabled identification of a phosphorylated peptide in the Cterminal region of the RTP, adding yet another layer of biological complexity to the virus proteins found within host cells. The peptide K.DATDGVSpSIGSGSLTGGTLK.R was identified as a doubly charged precursor ion at mass:charge ratio $(\mathrm{m} / \mathrm{z}) 951.94$, with a precursor mass measurement error of -0.46 parts per million (ppm) and an expected value (E-value) of $3.3 \mathrm{e}^{-07}$. The peptide spans amino acid residues 640 to 659 in the C-terminal domain of the RTP. To unambiguously assign the phosphorylation on S647, a combination of selected ion monitoring (SIM) and collision-induced dissociation (CID) was used to target the doubly charged ions of the nonphosphorylated and phosphorylated forms of the peptide K.DATDGVSpSIGSGS LTGGTLK.R and to obtain accurate mass measurements on both precursor and fragment ions. A subsequent CID spectrum from the nonphosphorylated peptide at $\mathrm{m} / z, 911.95 \pm 1$ was acquired with analysis of the fragment ions using highresolution and accurate mass measurements in the Orbitrap. The monophosphorylated peptide $(\mathrm{m} / \mathrm{z}$ ) was also targeted using SIM and CID. A SIM scan of range $911.95 \pm 5 \mathrm{~m} / z$ on the $N$. benthamiana $\alpha$-PLRV WT PLRV co-IP samples revealed a prominent peak at 76.46 min corresponding to the nonphosphorylated form of the peptide (Supplementary Fig. S5A and B). Surprisingly, the SIM scan targeting the phosphorylated peptide at 946.94 to $956.94 \mathrm{~m} / \mathrm{z}$ showed three peaks at retention times 78.55, 78.73, and 81.96 min (Supplementary Fig. S5C and D), indicating the presence of at least three positional isomers of the phosphorylated peptide. High-resolution and accurate mass CID spectra of the precursor ions of the nonphosphorylated and three monophosphorylated forms of the peptide are shown in Figure 4. CID fragmentation of the 951.94 $\mathrm{m} / \mathrm{z}$, precursor ion at retention time 78.33 to 78.54 showed a phosphorylation site at S650 or S652 but this assignment remains ambiguous because there were no fragment ions to distinguish between these two possibilities (Fig. 4B). The spectrum for phosphorylated peptide K.DATDGVSpSIGSGS LTGGTLK.R showed a mass difference of 367.1113 between fragment ion $y 14$ and $y 11$. Compared with the calculated sum of the nonphosphorylated fragment, 287.148, the mass shift of 79.9632 indicates phosphorylation rather than sulfation of S647, which would have a characteristic mass shift of 79.9568 (Fig. 4C). The unambiguous identification of these phosphorylated peptides confirms the presence of at least three additional
RTP isoforms (either incorporated or nonincorporated) available for mediating host or virus protein interactions in planta.

\section{Identification of viral and host proteins in complex with PLRV using high-resolution mass spectrometry.}

In total, 3,343 proteins were detected in the PLRV co-IP reactions (Supplementary Table S1). However, not all of these proteins are in the PLRV interactome; for example, many proteins bind to the beads or antibodies. To confidently assign proteins to the PLRV interactome, a structured data analysis strategy was required. First, spectral counting analysis was done using Scaffold (Koskinen et al. 2011; Nesvizhskii et al. 2003). We compared peptide spectral counts from infected $N$. benthamiana $\alpha$-PLRV co-IPs ( $n=7$ biological replicates) to negative control co-IPs: (i) IPs using mock-infiltrated tissue incubated with $\alpha$-PLRV-coated beads ( $n=3$ biological replicates) and (ii) PLRV-infected tissue with IgG-coated beads ( $n=10$ biological replicates). In total, 40 proteins were identified as common contaminants introduced during sample preparation (Mellacheruvu et al. 2013), including Protein A and IgG from the beads. The remaining 3,303 proteins were identified as being from $N$. benthamiana or PLRV.

The interaction specificity of proteins found in PLRV co-IPs was then assessed by using significance analysis of interactome (SAINT) (Choi et al. 2011, 2012), a software tool specifically developed for the analysis of data generated using co-IP coupled to nLC-MS/MS. SAINT statistically models spectral counts between negative controls (mock and $\mathrm{IgG}$ ) and bait (PLRV) co-IP samples in a semisupervised manner to calculate SAINT probability (SP) scores for putative interactions as well as a corrected fold-change (FC-A) value, which is related to the SP score by a sigmoid function (Choi et al. 2011, 2012). We chose a conservative SP threshold cutoff of $\geq 0.8$ based on published interactome studies in yeast and humans (Choi et al. 2011, 2012; Moon et al. 2014; Skarra et al. 2011; SmithKinnaman et al. 2014) and considered any prey protein matching this criteria as a putative interaction (direct or indirect) with PLRV or the structural proteins. Prey proteins with scores lower than 0.8 , due to significant detection in negative control IPs, were considered nonspecific or low-confidence interactions and removed from further bioinformatics analysis. Using SAINT parameters recommended for single-bait analysis, 1,566 of the 3,303 host and viral proteins had an SP score $\geq 0.8$ (Supplementary Table S2). An FC-A value based on the ratio of average normalized spectra counts in the bait IPs (PLRV) compared with the negative controls was calculated for

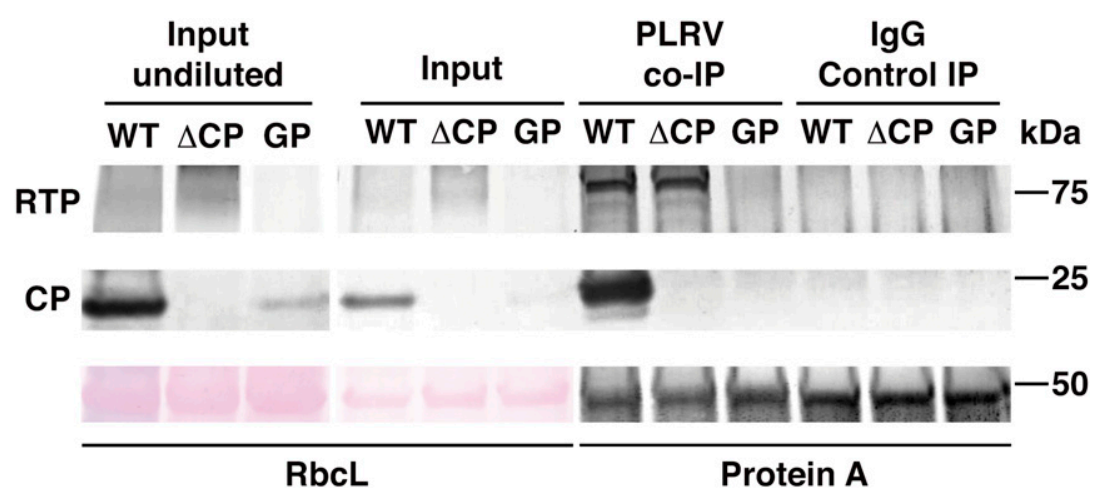

Fig. 3. Soluble form of PLRV readthrough protein (RTP) can be immunoprecipitated from infected plant tissue using our custom $\alpha$-PLRV raised against virus purified by sucrose density centrifugation. Western blot analysis of Protein A magnetic bead coimmunoprecipitation (co-IP) from Nicotiana benthamiana leaf tissue agroinfected with cDNA clones of the wild type (WT) or two mutant forms of PLRV that express only the soluble (nonassembled) forms of RTP ( $\triangle \mathrm{CP}$ ) and CP (GP) (Kaplan et al. 2007; Lee et al. 2005). Protein A-conjugated beads were coated with either $\alpha$-PLRV (IP) or an immunoglobulin G (C) control antibody and incubated with $1 \mathrm{ml}$ of infected lysate for $1 \mathrm{~h}$. CP and Protein A were detected using an alkaline phosphatase-conjugated $\alpha$-PLRV antibody (Agdia). Levels of $\mathrm{CP}$ in the co-IP input as well as the undiluted lysate (undiluted input) are shown. Ponceau staining shows levels of RbcL in co-IP inputs as loading controls. 

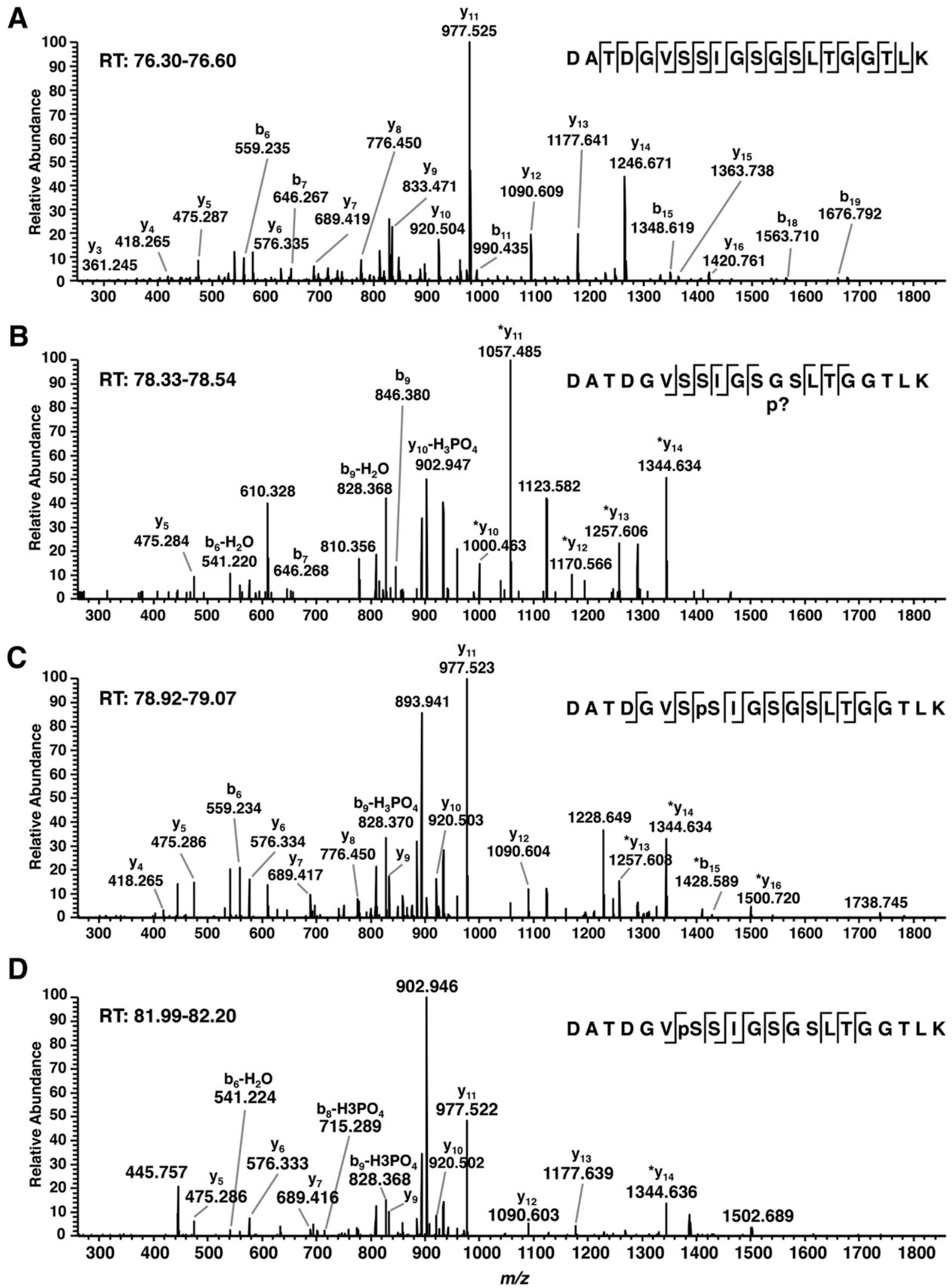

Fig. 4. High-resolution tandem mass spectrum $\left(\mathrm{MS}^{2}\right)$ produced using collision-induced dissociation (CID) in the Orbitrap mass analyzer of the A, nonphosphorylated form of readthrough protein (RTP) C-terminal peptide K.DATDGVSSIGSGSLTGGTLK.R $(\mathrm{m} / z$. 911.96) and B-D, three monophosphorylated forms $(\mathrm{m} / \mathrm{z}$ 951.94) targeted at retention times (RT) $\mathbf{A}, 76.30$ to $76.60 ; \mathbf{B}, 78.33$ to $78.54 ; \mathbf{C}, 78.92$ to 79.07 ; and $\mathbf{D}, 81.99$ to 82.20 min show fragment masses at high resolution. Asterisks $(*)$ indicate fragment ions with $+80 \mathrm{kDa}$ mass shifts corresponding to $\mathrm{PO}^{-4}: \mathbf{B}, y 10-14 ; \mathbf{C}, y 13-15$ and $b 15$; and $\mathbf{D}, y 14$. McLafferty plots showing fragmentation along the peptide backbone indicate the position of the assigned phosphorylation and other ions that were used in the assignment. An ambiguous site assignment is indicated with a $\mathrm{p}$ ? 
each prey protein. A small background factor was applied to prevent division by zero (Choi et al. 2011, 2012).

In addition to identifying host proteins in complex with PLRV structural proteins (incorporated or nonincorporated), we also identified three nonstructural viral proteins with SP scores above the threshold cutoff: the viral RNA-dependent RNA polymerase, the P1 polyprotein, and the P17 movement protein (Fig. 5). These viral proteins had SP scores of 1 and FC-A scores greater than 3 , both metrics indicating a high-scoring interaction with the PLRV structural proteins, directly or in complex.

\section{Functional characterization of the PLRV-host protein interaction network using bioinformatics.}

Although a draft sequence of the $N$. benthamiana genome has been released (Bombarely et al. 2012), programs that currently exist for functional characterization of plant proteins rely on reference data collected from studies done on the model plant system Arabidopsis thaliana. Therefore, to further characterize the function of $N$. benthamiana proteins in the identified PLRV-host interactome, we took a homology-based, bioinformatics approach using protein information available for A. thaliana orthologs corresponding to the $1,566 \mathrm{~N}$. benthamiana proteins found in our dataset to have an $\mathrm{SP} \geq 0.8$. Sequence comparison of proteins in our dataset revealed a number of $N$. benthamiana proteins sharing the same $A$. thaliana ortholog, indicating the co-IP of multiple family members with PLRV. We identified 746 unique $A$. thaliana orthologs sharing significant sequence homology to 1,468 $N$. benthamiana proteins in the PLRV-host interactome. These A. thaliana proteins were subsequently used for further functional studies. In all, 98 host proteins from the original 1,566 had no significant sequence homology to any proteins found in A. thaliana and were not analyzed further.

We used the Cytoscape plug-in ClueGO + Cluepedia (Bindea et al. 2009) to generate a gene ontology (GO) annotation (Reference Genome Group of the Gene Ontology Consortium et al. 2009) network based on biological processes, molecular functions, and Kyoto Encyclopedia of Genes and Genomes (KEGG) pathways (Kanehisa and Goto 2000; Kanehisa et al. 2014). In total, $100 \mathrm{GO}$ terms connected by 276 edges, representing $\kappa$ scores, exhibited significant enrichment $(P \leq 0.005)$ in the identified PLRV-host interactome relative to the entire

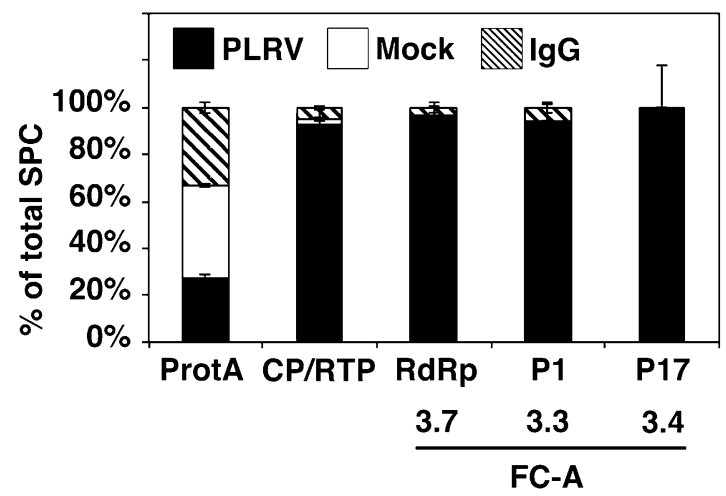

Fig. 5. Nonstructural viral proteins functioning in replication and movement are found coimmunoprecipitating with PLRV. Bar graph shows the percentage of total average spectral counts (SPC) for Protein A (ProtA), PLRV coat protein or readthrough protein (CP/RTP), viral RNA-dependent RNA polymerase (RdRp), P1 polyprotein, and the P17 movement protein found in $\alpha$-PLRV coimmunoprecipitation (co-IP) (black), mock (white), and immunoglobulin $\mathrm{G}$ (hatched) negative controls $(n=7,3$, and 10, respectively). Error bars indicate \pm standard error. A fold change value (FC-A) was calculated based on the ratio of average normalized spectral counts in PLRV co-IPs to negative controls and is listed below the prey protein name. Prey proteins shown here had a SAINT probability score of 1 .
A. thaliana reference genome (Fig. 6). Terms having the highest significance included those associated with cellular trafficking, cell wall biogenesis, membrane transport, plant defense, carbon fixation, and amino acid metabolism. A more detailed network can be accessed through Chorus.

We performed search tool for the retrieval of interacting genes or proteins (STRING) analysis (Franceschini et al. 2013; Szklarczyk et al. 2011) on the same 746 A. thaliana orthologs to determine whether host proteins found in the PLRV-host interactome function together in common pathways or cellular processes. In total, 14 separate functional interaction networks comprising 461 unique $A$. thaliana orthologs were assembled in STRING with a confidence score of $\geq 0.7$ (high), the largest of which contained 425 plant proteins connected by 3,540 interaction edges. Network connections were supported by evidence derived from experimental data, existing databases, and text mining. The interaction subnetworks identified corresponded to a set of host proteins in the PLRV-host interactome known to function together in key biochemical processes such as ion transport across the plasma membrane and central vacuole, clathrin-mediated endocytosis, exocytosis, amino acid biosynthesis, and protein import into plastids (Fig. 7). Both networks belong to the larger 425-protein interaction network and are connected to each other via the plant 14-3-3 protein GRF2. Protein nodes within the subnetworks (Fig. 7) are color coded according to their consensus subcellular localization predicted using the subcellular localization database for Arabidopsis proteins (SUBA3) (Tanz et al. 2013). The predicted consensus subcellular localizations for all 746 Arabidopsis orthologs are listed in Supplementary Table S3.

Comparison of plant proteins detected in the PLRV-host interactome with previously published data (Bencharki et al. 2010; Brizard et al. 2006; Cilia et al. 2012; Elena and Rodrigo 2012) shows that similar host proteins have been found interacting with other ssRNA+ viruses infecting plants (Table 1; Supplementary Table S4). We found $42 \mathrm{~N}$. benthamiana proteins within our dataset that shared functional homology or shared identical A. thaliana orthologs with plant proteins identified as copurifying with Cereal yellow dwarf virus, a polerovirus closely related to PLRV (Cilia et al. 2012). Twelve $N$. benthamiana proteins shared functional or sequence homology with cucumber sap proteins found interacting in vitro with the polerovirus Cucurbit aphid borne yellow virus (Bencharki et al. 2010). In total, $184 \mathrm{~N}$. benthamiana proteins were functional homologs of plant proteins identified by MS analysis as interacting in planta or in vitro with RYMV (Brizard et al. 2006), including several 14-3-3 proteins. Interestingly, we found $25 \mathrm{~N}$. benthamiana proteins that were orthologous to A. thaliana proteins identified as directly interacting with viral proteins expressed by species of Potyvirus (Elena and Rodrigo 2012), a distantly related genus of ssRNA+ viruses that differ from poleroviruses in genome organization, replication strategy, capsid structure, host tissue tropism, and mode of transmission (Riechmann et al. 1992). Those host proteins from the comparative study mentioned above that have been found interacting with multiple plant viruses, including lipoxygenase (EIG-J7), calreticulin (CRT3), glyceraldehyde-3-phosphate dehydrogenase (GAP), RuBisCO large subunit (RBCL), transketolase (TKTC), and adenosylhomocysteinases (HOG), are listed in Table 1.

\section{DISCUSSION}

ssRNA+ viruses are among the most abundant and devastating group of viruses infecting crop plants. Diversity among members of this group exists on many levels, including genome organization, capsid structure and composition, host specificity, 


\section{Hydrogen-exporting}

ATPase activity

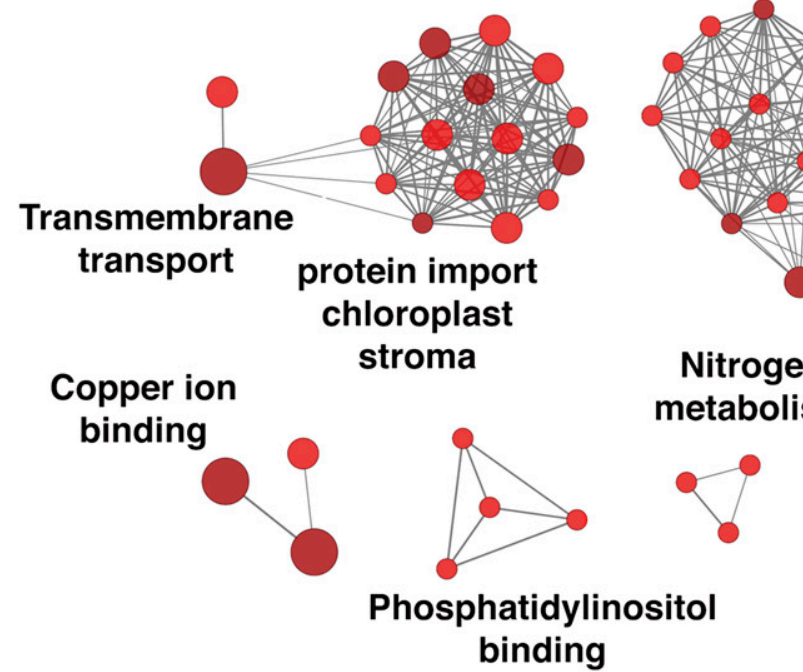

binding
ATP binding

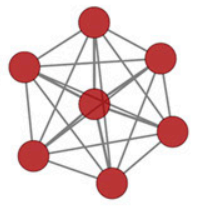

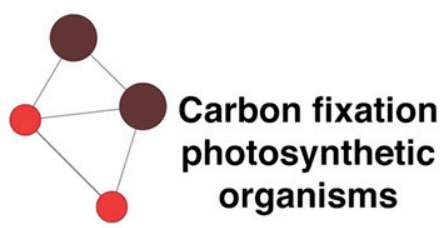

organisms

Cellular response to water deprivation

\begin{abstract}
Glycine metabolism
\end{abstract}

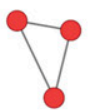

Clathrinmediated endocytosis

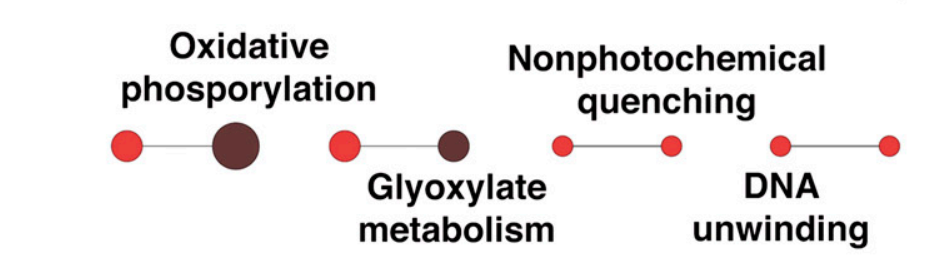

Response to cadmium ion
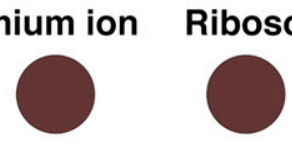

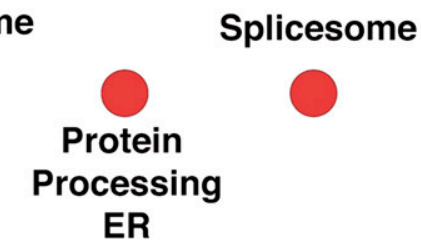

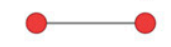

-

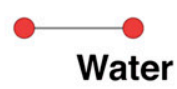

transport

\section{Defense response} to bacterium

Poly-pyrimidine tract binding

Translation
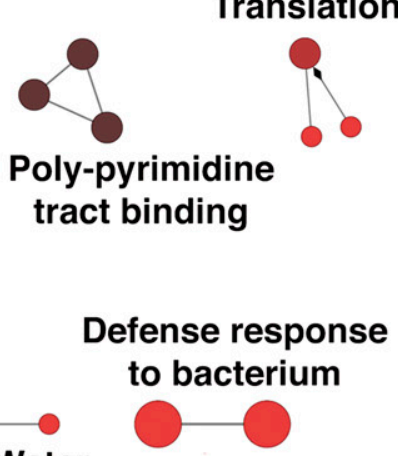

Response to water deprivation

\section{Endocytosis}

RNA transport
Citrate

cycle
Pyruvate metabolism
Ubiquitin protein ligase bindging
Protein secretion

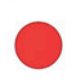

.




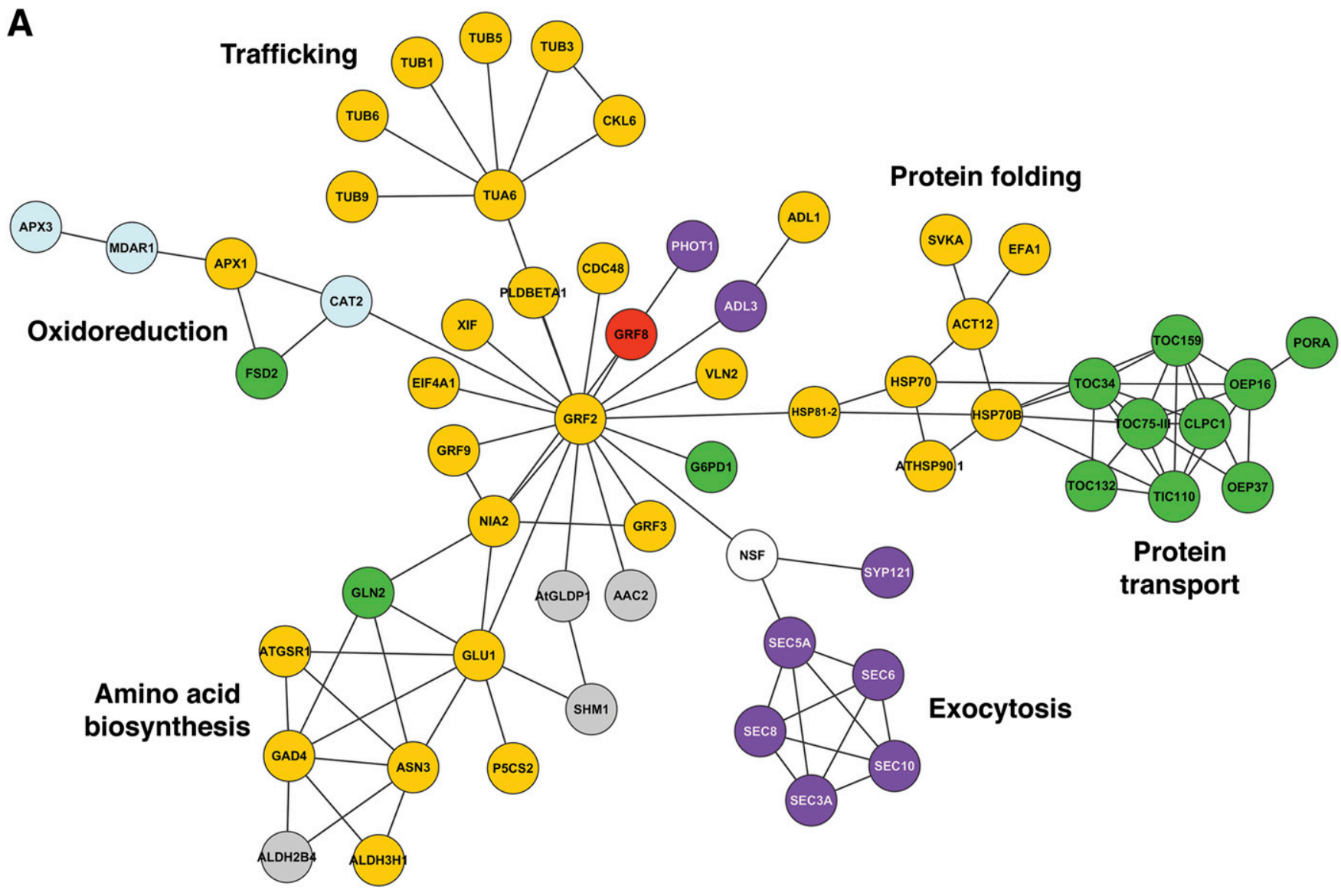

B

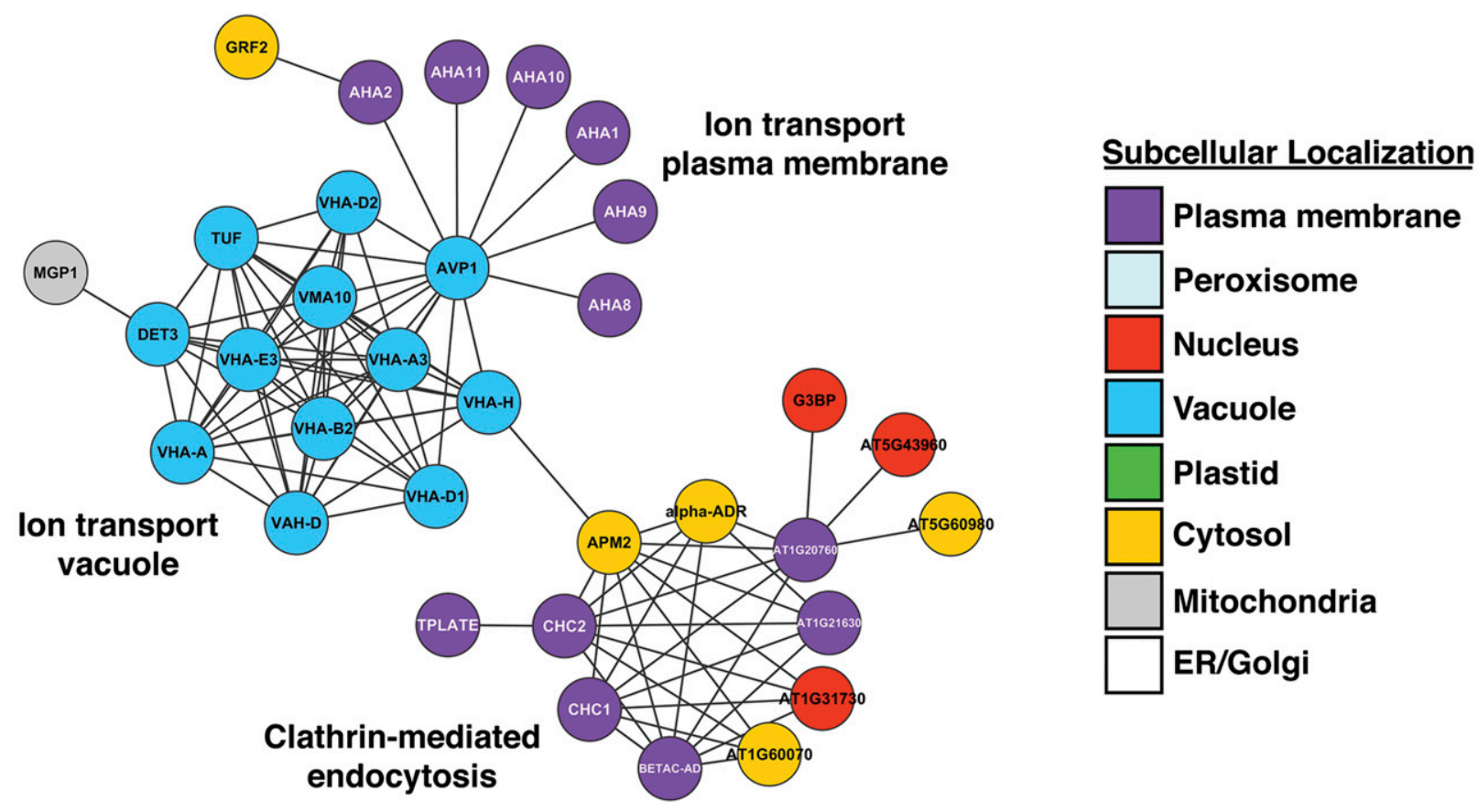

Fig. 7. Functional interaction network analysis of Arabidopsis thaliana orthologs corresponding to Nicotiana benthamiana proteins found in complex with PLRV identifies components regulating plant amino acid biosynthesis, membrane transport, and vesicle trafficking. A and B, STRING interaction networks of A. thaliana orthologs corresponding to a subset of $N$. benthamiana proteins found in complex with PLRV visualized in Cytoscape. Nodes represent a single protein and are color coded by their consensus subcellular localization predicted by the subcellular localization database for Arabidopsis proteins, SUBA3 (Tanz et al. 2013). Groups of nodes are labeled by their common gene ontology biological process assigned in UniProt (UniProt Consortium 2014). Edges represent significant evidence of a functional connection between proteins in the networks. Both networks were generated in STRING with a confidence score $\geq 0.7$ and center around the plant 14-3-3 protein GRF2. The full set of networks can be viewed in Supplementary Data S2. 
cellular tropism, symptom development, and mode of transmission (Di Carli et al. 2012; Gray et al. 2014; Zaccomer et al. 1995). Until recently, studies aimed at identifying proteinprotein interactions between virus and host have focused largely on binary interactions with nonstructural movement proteins involved in transporting viral nucleic acid-protein complexes cell to cell (Schoelz et al. 2011). However, poleroviruses move only as assembled virions and are unique, in that phloem retention is regulated by a viral structural protein in its nonincorporated form (Peter et al. 2009). In fact, there are many examples in the literature attributing nonstructural functions to viral capsid proteins during plant infection with different genera of plant viruses (Ivanov and Mäkinen 2012). Exactly how and in what form the capsid structural proteins regulate these different functions in plants is unknown but the logical conclusion from these studies is that they do so via tightly orchestrated interactions with host proteins.

From a technical standpoint, novel insights into PLRV-host molecular biology were attained using the co-IP workflow developed in this study (Fig. 1). Extraction of virus was improved by incubating cryolysed tissue in an HEPES-based buffer supplemented with the mild detergent TritonX-100, which is the most commonly used detergent for co-IPs of protein complexes from animal cells and tissues (Conlon et al. 2012). Surprisingly, Tween-20, another mild detergent structurally similar to TritonX-100 that is also often used in co-IPs (Conlon et al. 2012; Cristea et al. 2005), did not enhance the extraction of PLRV CP. The differential ability of these two detergents to extract PLRV CP suggests that PLRV may associate with membranes or vesicles with a specific type of lipid composition not amenable to extraction with Tween-20. Using our optimized co-IP method, we successfully enriched for PLRV RTP (incorporated and nonincorporated) and CP (incorporated) from infected plant tissue, whereas previous methods such as density gradient centrifugation resulted in a loss of the full-length and nonincorporated forms (Cilia et al. 2012; Filichkin et al. 1994; Perry et al. 1998; Wang et al. 1995). These data conclusively show that our method is an effective strategy to isolate host proteins in complex with the C-terminal domain of RTP that aids in actively regulating phloem tissue tropism but that may be missing from intact assembled virions (Boissinot et al. 2014). In addition, the co-IP of a variety of RTP sizes and posttranslationally modified isoforms supports the notion that poleroviruses may achieve biochemical flexibility in host cells by existing as different mulitmeric viral complexes during its life cycle.

We identified over 1,500 host proteins and 3 nonstructural viral proteins in complex with PLRV. Given the multiple forms of the virus structural proteins within plant cells described above, co-IP of three nonstructural viral proteins, and that $N$. benthamiana is a tetraploid having multiple copies of each protein (Marks et al. 2011), it is not surprising that so many host proteins were found to co-IP with PLRV. The methodology was sensitive enough to detect unique peptides identifying multiple protein paralogs with similar function being recruited by PLRV structural or nonstructural proteins. Functional characterization of the PLRV-host interactome through bioinformatics revealed a highly interconnected genetic network of host proteins involved in key biochemical pathways, including the carbon fixation cycle, amino acid biosynthesis, plant defense, and photosynthesis (Figs. 6 and 7; Supplementary Data S2), that have been shown by expression profiling to change upon infection with other viral species. This suggests that plant viruses may act to transcriptionally regulate those host proteins with which it needs to physically interact. Interestingly, the PLRV-host interactome is enriched for membrane-bound plant proteins that are known to function in regulating vesicle trafficking, ion transport, and protein import in other plant species (Figs. 6 and 7). There is increasing evidence that plant RNA viruses, like their animal counterparts, usurp and modify different membrane systems within host cells to promote their own replication and spread (Grangeon et al. 2012; Patarroyo et al. 2012). Transmission electron micrographs of PLRVinfected phloem cells have previously shown the association of virions with virus-induced vesicles in the cytoplasm, which are often observed fusing with organelles such as the nucleus, mitochondria, and vacuoles (Esau and Hoefert 1972; Shepardson et al. 1980). Peter and associates (2009) showed that truncation of the C terminus of RTP causes PLRV to move out of phloem into neighboring mesophyll cells, where the virus localizes along

Table 1. Nicotiana benthamiana proteins that putatively interact with Potato leafroll virus (PLRV) share functional similarity with proteins known to associate with multiple plant viruses

\begin{tabular}{|c|c|c|c|c|c|c|}
\hline Protein symbol $^{\mathbf{a}}$ & Number of proteins ${ }^{b}$ & RYMV $^{\mathbf{c}}$ & CYDV $^{d}$ & CABYV & Potyviruses $^{\mathbf{f}}$ & $\mathbf{F C} \mathbf{A}^{\mathbf{g}}$ \\
\hline RBS8 & 6 & $\nu$ & $\ldots$ & $\ldots$ & P3 & 1.37 \\
\hline RBCL & 2 & 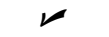 & $\ldots$ & $\ldots$ & P3 & 1.01 \\
\hline CRT3 & 3 & レ & $\ldots$ & $\ldots$ & HC-Pro & 3.19 \\
\hline EIG-J7 & 3 & 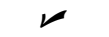 & $\ldots$ & $\nu$ & $\ldots$ & 2.04 \\
\hline GAP & 9 & 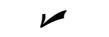 & 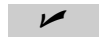 & $\ldots$ & $\ldots$ & 2.66 \\
\hline IBR3 & 1 & $\nu$ & レ & $\ldots$ & $\ldots$ & 4.57 \\
\hline TKTC & 2 & レ & $\nu$ & $\ldots$ & $\ldots$ & 2.36 \\
\hline ATLFNR2 & 1 & $\nu$ & $\nu$ & $\ldots$ & $\ldots$ & 2.20 \\
\hline HOG, SAHH2 & 5 & $\nu$ & $\nu$ & $\ldots$ & $\ldots$ & 3.08 \\
\hline GLDP & 3 & レ & $\nu$ & $\ldots$ & $\ldots$ & 3.30 \\
\hline ATCTIMC & 2 & 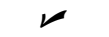 & $\nu$ & $\ldots$ & $\ldots$ & 2.01 \\
\hline
\end{tabular}

${ }^{a}$ Protein symbols manually curated from our in-house database corresponding to Nicotiana benthamiana proteins found coimmunoprecipitating with PLRV $(\mathrm{SP} \geq 0.8)$. See Supplementary Table S2 for protein common names.

b Number of protein family members found coimmunoprecipitating with PLRV.

${ }^{\mathrm{c}}$ Check indicates $N$. benthamiana proteins sharing functional homology with rice proteins identified by Brizard and associates (2006) as copurifying with Rice yellow mottle virus (RYMV).

d Check indicates $N$. benthamiana proteins sharing functional homology with oat proteins identified by Cilia and associates (2012) as copurifying with Cereal yellow dwarf virus (CYDV). The gray box indicates interacting proteins that share a common A. thaliana ortholog.

e Check mark indicates $N$. benthamiana proteins sharing functional homology with proteins from cucumber sap shown by Bencharki and associates (2010) to interact in vitro with Cucurbit aphid borne yellow virus (CABYV).

${ }^{\mathrm{f}} \mathrm{N}$. benthamiana proteins sharing sequence homology with A. thaliana proteins shown to interact with Potyvirus viral proteins (Elena and Rodrigo 2012). The gray box indicates proteins found in complex with PLRV that share a common A. thaliana ortholog with proteins identified interacting with the indicated virus. P3 = movement protein and HC-Pro = a protease with RNA silencing suppressor activity.

${ }^{\mathrm{g}}$ Fold-change calculation based on the ratio of average normalized spectral counts in PLRV coimmunoprecipitation to negative controls (calculation described on the Crapome webserver) for representative $N$. benthamiana protein. 
the outer envelope of chloroplasts. Based on what is known about the subcellular localization of other plant viruses, such as Tobacco mosaic virus (Liu and Nelson 2013), it has been proposed that these PLRV-associated vesicles may serve as sites of viral replication (Shepardson et al. 1980). However, Golinowski and associates (1987) showed that these vesicles could be observed forming near or fusing with endoplasmic reticulum membranes associated with plasmodesmata, lending support to the hypothesis that these PLRV-induced vesicles may also serve as a means for trafficking the virus cell to cell. In aphids, movement of luteovirid across tissue barriers within the gut and accessory salivary glands occurs via clathrin-mediated endocytosis (Gray and Gildow 2003). In this study, we identified several plant proteins regulating clathrin-mediated endocytosis coimmunoprecipitating with virion (Fig. 7), suggesting that PLRV may be using a similar mode of trafficking within its host and vector.

Some of these membrane-bound, PLRV-interacting host complexes form a distinct functional network connected by the 14-3-3 phospho serine/threonine binding protein GRF2, which is involved in signal transduction. (Fig. 7). This particular network linked interactions at the plasma membrane to the vacuole and was composed of proteins involved in endomembrane trafficking. It is known that retrograde transport used by other plant viruses is associated with endocytosis, where cargo is returned from the plasma membrane through endosomes to the vacuole (Schoelz et al. 2011). In both plant and mammalian cells, activation of signaling cascades by the phosphorylation-dependent binding of 14-3-3 proteins to various cellular proteins leads to the development of innate immunity responses against bacteria and viruses, respectively (Oh and Martin 2011; Öhman et al. 2014). Other processes controlled by 14-3-3 proteins in plants include nitrogen and carbon assimilation, transcription, regulation of enzymes involved in metabolism, and activation of plasma membrane $\mathrm{H}^{+}$ATPases (DeLille et al. 2001). Six $\mathrm{H}^{+}$ATPases were observed to coimmunoprecipitate with PLRV (Fig. 7).

Dunker and associates (1998) postulated the existence of signaling hubs such as the 14-3-3 hub described above and the important role played by intrinsic protein disorder, or a lack of a stable three-dimensional structure, in the formation and function of these hubs. It is widely accepted that intrinsic protein disorder plays a key role in protein interactions and the construction of in vivo protein interaction networks (Uhart and Bustos 2014). The C-terminal domain of the polerovirus RTP is predicted to be highly disordered (Boissinot et al. 2014; Chavez et al. 2012; Gray et al. 2014), which would facilitate interaction with a large number of host proteins. The phosphorylated RTP isoforms would provide additional binding flexibility for protein interaction with host or viral partners. A recent report shows that the processes of phosphorylation, binding, and disorder-order transitions are coupled to each other (Nishi et al. 2013).

Comparison of host proteins found interacting with PLRV to those identified in complex with other plant viruses (Bencharki et al. 2010; Brizard et al. 2006; Elena and Rodrigo 2012) indicates that some of these points of contact within hosts may be common among ssRNA viruses infecting plants, underscoring the idea that natural selection has favored plant viruses to exploit common nodes within host cellular pathways (Table 1). One class of host proteins found to interact with several icosahedral shaped viruses, HOG, has been shown to be required for DNA methylation-dependent gene silencing (Rocha et al. 2005). In plants, RNA-directed DNA methylation (RdDM) is the major small-interfering RNA (siRNA)-mediated pathway that regulates epigenetic changes within the genome as well as acts as a defense mechanism against RNA pathogens (Matzke and Mosher 2014). In an elegant demonstration of the evolutionary "arms race" that exists between host and pathogen, plant viruses, in turn, encode suppressor proteins that interfere with host silencing (Pumplin and Voinnet 2013). The canonical viral suppressor protein of PLRV, referred to as P0, inhibits silencing by targeting degradation of Argonaute 1 (AGO1), the protein that binds siRNAs and guides cleavage of viral RNA as well as endogenous mRNAs within the plant, leading to posttranscriptional gene silencing (Baumberger et al. 2007). In the RdDM pathway, siRNAs are loaded into Argonaute 4 (AGO4), which act to guide de novo methylation of plant DNA leading to epigenetic silencing (Matzke and Mosher 2014). In this study, we identified both AGO1 and AGO4 in complex with PLRV as well as $N$. benthamiana proteins with functional homology to other components involved in the RdDM pathway, including histone deacetylase and histonelysine N-methyltransferase, which are involved in establishment of repressive histone modifications (Casas-Mollano et al. 2006; Wu et al. 2000). Remarkably, we did not detect P0 within our PLRV co-IPs, indicating that poleroviruses may have evolved additional strategies for repression or manipulation of host gene silencing and epigenetic modifications that involve interaction with the viral structural proteins or the three nonstructural proteins we identified in the PLRV-host interactome.

Although we have demonstrated that co-IP coupled to mass spectrometry-based proteomics is a powerful, high-throughput approach to characterizing viral interactomes in a single experiment, future work still remains in identifying the binary interactions that make up the PLRV-host network to better understand exactly how PLRV exploits the host protein machinery to further its own propagation and transmission. Ultimately, integration of datasets generated using methods that verify protein function, direct protein binding such as yeasttwo-hybrid or chemical cross-linking technologies (Chavez et al. 2011), and "-omics" scale datasets will enable fine mapping of entire host-virus protein interaction networks. Such information will be helpful to guide plant molecular biologists and breeders in generating novel modes of virus resistance.

\section{MATERIALS AND METHODS}

\section{Plant infection.}

Agrobacterium tumefaciens cultures (strain LB4404) containing the full-length cDNA of WT PLRV or CP mutants (Kaplan et al. 2007) were grown overnight at $28^{\circ} \mathrm{C}$ in Luria Bertani medium supplemented with kanamycin $(50 \mu \mathrm{g} / \mathrm{ml})$, rifampicin $(50 \mu \mathrm{g} / \mathrm{ml}), 1.7 \mathrm{mM}$ magnesium sulfate $\left(\mathrm{MgSO}_{4}\right)$, and $20 \mu \mathrm{M}$ acetosyringone. Pelleted $A$. tumefaciens cells were resuspended to an optical density at $600 \mathrm{~nm}$ of 0.3 to 0.4 in $10 \mathrm{mM}$ magnesium chloride $\left(\mathrm{MgCl}_{2}\right), 1 \mathrm{mM} 2$-( $N$-morpholino $)$ ethanesulfonic acid $\mathrm{pH}$ 5.6, and $100 \mu \mathrm{M}$ acetosyringone and infiltrated into leaves of 4- to 5-week-old $N$. benthamiana plants. Leaf tissue was harvested 3 days postinfiltration and stored at $-80^{\circ} \mathrm{C}$ for co-IP experiments.

\section{Cryogenic lysis of plant tissue.}

Leaf tissue was ground to a coarse powder in liquid nitrogen using a mortar and pestle. Crushed samples were then cryogenically lysed using a mixer mill MM 400 (Retsch). Cylinders, plus stainless steel balls for the MM 400, were chilled in liquid nitrogen for $30 \mathrm{~min}$ prior to use. Approximately 5 to $6 \mathrm{~g}$ of tissue was ground for three sets of 3-min grinds at a vibrational frequency of $30 \mathrm{~Hz}$. Between each cycle, the cylinders were cooled in liquid nitrogen for $5 \mathrm{~min}$. After cryolysis, samples were stored at $-80^{\circ} \mathrm{C}$ for Western analysis and co-IP experiments. To test the efficiency of cryolysis by Western analysis, total protein was extracted from $200 \mathrm{mg}$ of hand- and machinemilled PLRV-infected $N$. benthamiana leaf tissue in $1 \mathrm{ml}$ of $1 \times$ PBS, pH 7.4, supplemented with $0.5 \mathrm{mM}$ phenylmethylsulfonyl 
fluoride (PMSF) (Sigma-Aldrich, St. Louis) and a 1:100 dilution of Halt EDTA-free protease inhibitor cocktail (PI) (Pierce, Rockford, IL, U.S.A.). Concentration of total protein in each extraction was determined using Quick Start Bradford 1× Dye Reagent (Bio-Rad, Hercules, CA, U.S.A.) following the manufacturer's instructions.

For microscopic analysis, $200 \mathrm{mg}$ of tissue was gently resuspended in $1 \mathrm{ml}$ of $50 \mathrm{mM}$ HEPES-KOH (pH 7.4), $110 \mathrm{mM}$ potassium acetate (KOAc), and $2 \mathrm{mM} \mathrm{MgCl}_{2}$. Homogenate $(20 \mu \mathrm{l})$ from each sample was imaged using bright-field illumination with a $\times 20$ water immersion objective on a DM5500 epifluorescence microscope (Leica, Buffalo Grove, IL, U.S.A.). Images were captured using Q-Capture Pro 6.0 software (QImaging, Surrey, BC, Canada).

\section{Optimization of lysis buffer conditions.}

$N$. benthamiana leaf tissue infected with WT PLRV was cryogenically lysed using a mixer mill MM 400 (Retsch) and resuspended in the following lysis buffers: buffer $1=1 \times$ PBS, $\mathrm{pH} 7.4$; buffer $2=$ buffer 1 supplemented with $0.5 \mathrm{mM}$ PMSF and a 1:100 dilution of PI; buffer $3=50 \mathrm{mM}$ HEPES-KOH (pH 7.4), $110 \mathrm{mM}$ KOAc, $2 \mathrm{mM} \mathrm{MgCl}_{2}, 0.5 \mathrm{mM}$ PMSF, and PI $(1: 100)$; buffer $4=$ buffer 3 supplemented with $0.1 \%$ TritonX100 ; buffer $5=$ buffer 3 supplemented with $0.4 \%$ TritonX-100; buffer $6=$ buffer 3 supplemented with $0.4 \%$ Tween-20; buffer $7=50 \mathrm{mM}$ Tris-HCL (pH 7.5), $150 \mathrm{mM} \mathrm{NaCl}, 0.4 \%$ TritonX$100,0.5 \mathrm{mM}$ PMSF, and PI (1:100); and buffer $8=50 \mathrm{mM}$ TrisHCL (pH 6.8), 2.5\% sodium dodecyl sulfate (SDS), $10 \%$ glycerol, and $100 \mathrm{mM}$ dithiothreitol. Total protein was extracted following the lysis protocol outlined in (Cristea and Chait 2011). Samples were incubated at $4^{\circ} \mathrm{C}$ for $24 \mathrm{~h}$ or approximately $20 \mathrm{~min}$ on ice. Tissue was then homogenized in buffer on ice with a Polytron (Brinkmann Instruments, Rexdale, ON, Canada) for two 10-s pulses at setting 2, separated by a 30 -s incubation on ice. Lysates were rotated at $4^{\circ} \mathrm{C}$ for $10 \mathrm{~min}$ and centrifuged at $3,000 \mathrm{rpm}$ for $10 \mathrm{~min}$ at $4^{\circ} \mathrm{C}$ to remove all cell debris. The concentration of total protein in each extraction was determined using Quick Start Bradford 1× Dye Reagent (Bio-Rad) following the manufacturer's instructions. Absorbance values resulting from the minimal background reactivity of detergents in each buffer with the Bradford regent were subtracted from the absorbance readings measured for the respective protein extraction. The protein concentration for each sample was calculated using a best-fit second-order polynomial equation generated from a standard curve.

\section{Antibody preparation.}

PLRV was purified from systemically infected $P$. floridiana via sucrose density centrifugation (Perry et al. 1998) and used as the antigen for polyclonal antibody production in rabbit by Cocalico Biologicals, Inc. (Reamstown, PA, U.S.A.). Serum was cross-absorbed against cryolysed $N$. benthamiana leaf tissue mock infiltrated with A. tumefaciens strain LB4404 and the $\mathrm{IgG}$ fraction concentrated by sodium sulfate precipitation.

\section{co-IP of PLRV-host complexes using magnetic beads.}

Rabbit IgG (Promega Corp., Madison, WI, U.S.A.) or $\alpha$-PLRV antibody was bound to Dynabeads Protein A (Life Technologies, Grand Island, NY, U.S.A.) at a concentration of $10 \mu \mathrm{g}$ of antibody per $1.5 \mathrm{mg}$ of beads following the manufacturer's instructions in 2.0-ml, round-bottom, Protein LoBind microfuge tubes (Eppendorf, Hamburg, Germany). Antibodycoated beads were stored at $4^{\circ} \mathrm{C}$ for approximately $60 \mathrm{~min}$ in $1 \times$ PBS (pH 7.4) and $0.02 \%$ Tween-20 until co-IP. For each co-IP and control, $4 \mathrm{~g}$ of cryogenically lysed $N$. benthamiana leaf tissue (infected and controls) was resuspended in $20 \mathrm{ml}$ of lysis buffer (50 mM HEPES-KOH [pH 7.4], $110 \mathrm{mM}$ KOAc, $2 \mathrm{mM}$
$\mathrm{MgCl}_{2}, 0.4 \%$ TritonX-100, 0.5 mM PMSF [Sigma-Aldrich] and a 1:100 dilution of Halt EDTA-free PI [Pierce]) and viralprotein complexes were extracted following the 30-min incubation protocol outlined above for optimization of lysis buffer conditions. Antibody-coated beads were washed once with $1 \mathrm{ml}$ of lysis buffer and gently resuspended in fresh lysis buffer at a concentration of $30 \mu \mathrm{g}$ of beads per milliliter of buffer.

Lysate $(20 \mathrm{ml})$ diluted 1:5 in fresh lysis buffer was split evenly into two 15-ml falcon tubes (VWR, Radnor, PA, U.S.A.) and $10 \mathrm{mg}$ of either IgG or $\alpha$-PLRV antibody-coated beads were added to each $10 \mathrm{ml}$. Virion-host protein complexes were immunoprecipitated for $1 \mathrm{~h}$ at $4^{\circ} \mathrm{C}$ with gentle rotation. Beads were then separated and washed four times in $1 \mathrm{ml}$ of lysis buffer followed by two times in $1 \mathrm{ml}$ of $1 \times$ PBS $(\mathrm{pH} 7.4)$ in Protein LoBind microfuge tubes. At each washing step, tubes were changed and beads gently resuspended with a pipette. At the last washing step, bead volume was split in half and magnetically separated from buffer for SDS-polyacrylamide gel electrophoresis (PAGE) or Western analysis and on-bead digestion, respectively.

\section{SDS-PAGE and Western analysis.}

Co-IP and input fractions were either eluted or diluted (1:1), respectively, in $2 \times$ Laemmli Sample Buffer (Bio-Rad) supplemented with $5 \%$ (vol/vol) 2-mercapethanol, incubated at $70^{\circ} \mathrm{C}$ for $10 \mathrm{~min}$ and separated on a $10 \%$ Mini-PROTEAN TGX precast gel (Bio-Rad). To visualize proteins coimmunoprecipitating with virion, gels were stained with SYPRO Ruby stain (Invitrogen, Carlsbad, CA, U.S.A.) following the manufacturer's instructions and imaged on a Typhoon Variable Mode Imager (GE Healthcare, Pittsburgh). For Western analysis, proteins were transferred to $0.45 \mu$ of NitroBind Pure Nitrocellulose (GE Water and Process Technologies, Trevos, PA, U.S.A.) using the Mini-PROTEAN tetra cell wet-transfer system (Bio-Rad). Wet transfer was performed at $4{ }^{\circ} \mathrm{C}$ and $80 \mathrm{~V}$ for $1.5 \mathrm{~h}$ using $20 \%$ methanol, $24.8 \mathrm{mM}$ Tris, and $191.8 \mathrm{mM}$ glycine buffer. Blots were blocked in 5\% nonfat dry milk (Best Yet, Bethpage, NY, U.S.A.) dissolved in $1 \times$ Tris-buffered salineTween $(0.5 \%$ Tween-20) (TBST) overnight at room temperature with gentle agitation. Blots were probed with a 1:200 dilution of the alkaline phosphatase-conjugated PLRV detection antibody from Agdia (Elkhart, IN, U.S.A.) in $0.1 \%$ bovine serum albumin (Sigma-Aldrich) and $1 \times$ TBST for $1 \mathrm{~h}$ at room temperature. Blots were washed three times with $1 \times$ TBST and once with $1 \times$ TBS before development with 1-Step nitroblue tetrazolium/5-bromo-4-chloro-3-indolyl phosphate (Pierce). All blots were stained with $0.1 \%$ Ponceau $\mathrm{S}$ in $1 \%$ (vol/vol) acetic acid for $3 \mathrm{~min}$ and destained in $\mathrm{dH}_{2} \mathrm{O}$. The relative densities of band peaks were measured using the measure tool for gel analysis (Schneider et al. 2012) in ImageJ64 version $1.47 \mathrm{t}$.

\section{Sample preparation for mass spectrometry.}

Magnetic beads from $\alpha$-PLRV and IgG co-IPs were resuspended in $50 \mu \mathrm{l}$ of $0.1 \%$ ProteaseMAX surfactant, trypsin enhancer (Promega Corp.) in $50 \mathrm{mM}$ ammonium bicarbonate. Tris (2-carboxyethyl)phosphine hydrochloride was added to a final concentration of $5 \mathrm{mM}$, and disulfide bonds were reduced for $20 \mathrm{~min}$ at $55^{\circ} \mathrm{C}$. Samples were cooled to room temperature for $10 \mathrm{~min}$ and methyl methanethiosulfonate was added to a final concentration of $10 \mathrm{mM}$. Alkylation was allowed to proceed for $20 \mathrm{~min}$ at room temperature. On-bead protein digestion was carried out overnight at $37^{\circ} \mathrm{C}$ using $2 \mu \mathrm{g}$ of sequencing grade modified trypsin (Promega Corp.) reconstituted in the trypsin buffer supplied by the manufacturer. Sample volume was kept at a minimum throughout. Beads were 
magnetically separated from the supernatant using a DynaMag2 (Life Technologies) and supernatants were dried down in a centrifugal vacuum concentrator. Peptides were stored at $-80^{\circ} \mathrm{C}$ until analyzed by mass spectrometry.

\section{Mass spectrometry.}

Tryptic digests of co-IPs were solubilized in $50 \mu \mathrm{l}$ of $0.2 \%$ trifluoracetic acid and $2 \%$ acetonitrile by vortexing for $10 \mathrm{~min}$ at $37^{\circ} \mathrm{C}$ and bath sonication for $5 \mathrm{~min}$. The solubilized digests were centrifuged at $10,000 \times g$ for 5 min and the supernatants were carefully removed and placed into autosampler vials. All mass spectrometry was performed on an LTQ-Orbitrap-Velos (Thermo Fisher Scientific, San Jose, CA, U.S.A.), and the order of sample analysis was randomized. At least $1 \mu \mathrm{g}$ of each sample digest was loaded onto a $150-\mu \mathrm{m}$ Kasil fritted trap packed with Jupiter C12 90- $\AA$ material (Phenomenex, Torrance, CA, U.S.A.) to a bed length of $2 \mathrm{~cm}$ at a flow rate of $2 \mu \mathrm{l} / \mathrm{min}$. After loading and desalting using a total volume of $10 \mu \mathrm{l}$ of $0.1 \%$ formic acid plus $2 \%$ acetonitrile, the trap was brought online with a pulled fused-silica capillary tip $(75-\mu \mathrm{m}$ i.d.) packed with $40 \mathrm{~cm}$ of Reprosil-Pur C18-AQ (3- $\mu \mathrm{m}$ bead diameter; Dr. Maisch) mounted in an in-house-constructed microspray source and placed in line with a Waters Nanoacquity binary UPLC pump plus autosampler. Peptides were eluted off the column using a gradient of 2 to $35 \%$ acetonitrile in $0.1 \%$ formic acid over $120 \mathrm{~min}$, followed by 35 to $60 \%$ acetonitrile over $10 \mathrm{~min}$ at a flow rate of $250 \mathrm{nl} / \mathrm{min}$.

The mass spectrometer was operated using data-dependent acquisition, where a maximum of $15 \mathrm{MS} / \mathrm{MS}$ spectra were acquired per MS spectrum. Gas phase fractionation (Davis et al. 2001; Spahr et al. 2001) was employed by injecting each sample three times with MS scan ranges of $\mathrm{m} / \mathrm{z} 400$ to 550,545 to 800 , and 795 to 1600 . The resolution for MS was 60,000 at $\mathrm{m} / \mathrm{z}, 400$, and for MS/MS the linear ion trap provided unit resolution. The automatic gain control targets for MS in the Orbitrap was $1 \mathrm{e}^{6}$ whereas, for MS/MS, it was 8,000, and the maximum fill times were 20 and $80 \mathrm{~ms}$, respectively. The MS/MS spectra were acquired using an isolation width of $2 \mathrm{~m} / \mathrm{z}$ and a normalized collision energy of 35 . The precursor ion threshold intensity was set to 5,000 to trigger an MS/MS acquisition. MS/MS acquisitions were prevented for precursor charge states of +1 , or if the charge state could not be discerned from the MS spectrum. Dynamic exclusion (including all isotope peaks) was set for $30 \mathrm{~s}$.

To validate the identification of phosphorylated peptides, additional liquid chromatography MS data were acquired specifically targeting the doubly charged ions of nonphosphorylated and monophosphorylated DATDGVSpSIGSGSLTGGTLK at $\mathrm{m} / \mathrm{z}, 911.95$ and 951.94, respectively. SIM using the Orbitrap analyzer allowed for greater sensitivity in the measurement of the precursor ion masses, and was performed at a resolution of 60,000 FWHM (full width half maximum) at $\mathrm{m} / \mathrm{z}, 400$ and an automatic gain control (AGC) target of $1 \mathrm{e}^{5}$, with a maximum fill time of $30 \mathrm{~ms}$. CID spectra were acquired on each of these two precursor masses with an isolation width of $\mathrm{m} / \mathrm{z}=2$, and the fragment ions were analyzed using the orbitrap at a resolution of 7,500, an AGC target of $5 \mathrm{e}^{5}$, and a maximum fill time of $128 \mathrm{~ms}$. These series of SIM and CID spectra were continuously acquired, with a total cycle time of approximately $4 \mathrm{~s}$. This allowed for increased sensitivity and the ability to monitor closely eluting positional phosphovariants.

All raw mass spectrometry files pertaining to this manuscript are publicly available for download from the proteomic data repository webserver Chorus (project PLRV_N_benth_co-IP_Data_2014).

\section{Database searching and label-free quantification of mass spectrometry data.}

The database used for protein identification was created inhouse using amino acid sequences corresponding to all coding gene sequences from the recently released draft genome of $N$. benthamiana, amino acid sequences from species of Luteoviridae, and common animal contaminant protein sequences obtained from the National Center for Biotechnology Information (NCBI). This $N$. benthamiana database is available for download. Mass spectrometry data were converted into Mascot generic format files using tools in Proteowizard (Kessner et al. 2008) and searched using an in-house Mascot server v2.3.02 (Perkins et al. 1999), as follows: carbamidomethylation was considered as a fixed modification on cysteine residues. The following variable modifications were considered: oxidation of methionine and deamidation of glutamine, asparagine, and phosphorylation on serine and theronine. One missed tryptic cleavage was allowed. Mass measurement accuracy of $30 \mathrm{ppm}$ was set for precursor ions and 0.8 Da fragment ions. Mascot scores, expect values, emPAI, and ion scores were determined after Percolation (Käll et al. 2007). Search results were converted into Mascot .dat files and imported into Scaffold v4.2.1 (Proteome Software, Portland, OR, U.S.A.) for label-free quantification by spectral counting using the protein-clustering feature (Koskinen et al. 2011; Nesvizhskii et al. 2003; Pinheiro et al. 2014). Phosphopeptide spectra were manually assigned with assistance from the MS-Product software tool in Protein Prospector. Spectra were filtered in Scaffold with a local false discovery rate of $1 \%$ for peptide and protein and a two-peptide minimum for protein identification.

\section{SAINT analysis.}

Total spectral counts for each protein identified in the $N$. benthamiana $\alpha$-PLRV co-IPs and their respective counts in the negative controls were taken for interaction probability scoring using the SAINT webserver (Mellacheruvu et al. 2013). Spectral count data were manually reformatted to generate a SAINT input list, as described on the Crapome website. For low stringent analysis of the single WT PLRV bait experiment, the following SAINT options were used: lowmode $=0$, minfold $=0$, and norm $=0$ (Choi et al. 2012). co-IP s preformed with mock A. tumefaciens-infiltrated tissue and IgG-coated Protein A beads were used as negative controls, with the virtual control threshold being set to 10 . The spectral count for the PLRV CP/ RTP bait protein was set to zero in its purification. The final SP score for each bait-prey pair was computed as an average of the individual probabilities for each biological replicate. FC-A values were calculated by the Crapome webserver using spectral counts from our negative control IPs. Host proteins with an SP score $\geq 0.8$ were considered to have high confidence interaction with PLRV virion or the nonincorporated form of RTP. NCBI accession numbers for featured proteins include gi|1480567 (Protein A), gi|9629162 (PLRV P1), and gi|9629165 (PLRV P17). Protein reference sequence numbers for host proteins and PLRV CP.RTP correspond to sequences found in our annotated in-house protein database.

\section{Interaction network analysis.}

The Cytoscape (v3.0.2) plugin ClueGO + Cluepedia v2.1.3 (Bindea et al. 2009) was used to identify statistically enriched GO categories in the PLRV-host-protein interactome. The analysis was performed using the unique Arabidopsis orthologs of $N$. benthamiana proteins found to form high-confidence interactions ( $\mathrm{SP} \geq 0.8$ ) with PLRV. GO categories searched include biological processes, molecular function, and KEGG pathways with evidence inferred by all experimental data and electronic annotation. The GO level interval was set at a minimum $=5$ and a maximum level $=11$, with a two-gene minimum per category. Analysis was performed using a rightsided hypergeometric test for enrichment against the ClueGO Arabidopsis reference genome. GO terms with $\mathrm{pV} \leq 0.05$ after 
using the Benjamini and Hochberg false discovery rate correction were reported.

Functional interaction network analysis of the unique Arabidopsis orthologs corresponding to host proteins in complex with PLRV was performed using the web-based STRING database, v9.0. Parameters used to assemble the networks included a confidence scoring of $\geq 0.7$ and the following prediction methods: experimental evidence, text mining, and existing databases. Disconnected nodes were removed and the resulting STRING networks were imported into Cytoscape v3.0.2 (Smoot et al. 2011) for visualization. The subcellular localizations of orthologs were categorized according to the consensus localization obtained using SUBA3 (Tanz et al. 2013).

\section{ACKNOWLEDGMENTS}

We thank two anonymous reviewers for their critical feedback to improve the manuscript, T. Greco and I. Cristea (Princeton) for helpful discussion, K Rivera at Cold Spring Harbor Laboratory for feedback on methods, members of the Cilia lab for assistance with manually reviewing the spectra derived from the modified peptides and providing comments on the manuscrip drafts, J. VanEe and J. Flaherty at Cornell University's Institute for Biotechnology Bio-IT Facility for IT support, T. Hammond (Cornell) for care of plants, G. Martin (Boyce Thompson Institute) for access to the $N$. benthamiana genome sequencing data, and M. Srivastava at the Boyce Thompson Institute Plant Cell Imaging Center for help with imaging. Funding was provided by USDA NIFA grant 1907-22000-021-20, the Boyce Thompson Institute, and NSF grants 1109989 and 1354309.

\section{LITERATURE CITED}

Bahner, I., Lamb, J., Mayo, M. A., and Hay, R. T. 1990. Expression of the genome of Potato leafroll virus: Readthrough of the coat protein termination codon in vivo. J. Gen. Virol. 71:2251-2256.

Baumberger, N., Tsai, C. H., Lie, M., Havecker, E., and Baulcombe, D. C. 2007. The Polerovirus silencing suppressor P0 targets ARGONAUTE proteins for degradation. Curr. Biol. 17:1609-1614.

Bencharki, B., Boissinot, S., Revollon, S., Ziegler-Graff, V., Erdinger, M., Wiss, L., Dinant, S., Renard, D., Beuve, M., Lemaitre-Guillier, C., and Brault, V. 2010. Phloem protein partners of Cucurbit aphid borne yellows virus: Possible involvement of phloem proteins in virus transmission by aphids. Mol. Plant-Microbe Interact. 23:799-810.

Bindea, G., Mlecnik, B., Hackl, H., Charoentong, P., Tosolini, M., Kirilovsky, A., Fridman, W. H., Pagès, F., Trajanoski, Z., and Galon, J. 2009. ClueGO: A Cytoscape plug-in to decipher functionally grouped gene ontology and pathway annotation networks. Bioinformatics 25: 1091-1093.

Boissinot, S., Erdinger, M., Monsion, B., Ziegler-Graff, V., and Brault, V. 2014. Both structural and non-structural forms of the readthrough protein of Cucurbit aphid-borne yellows virus are essential for efficient systemic infection of plants. PLoS One 9:e93448.

Bombarely, A., Rosli, H. G., Vrebalov, J., Moffett, P., Mueller, L. A., and Martin, G. B. 2012. A draft genome sequence of Nicotiana benthamiana to enhance molecular plant-microbe biology research. Mol. PlantMicrobe Interact. 25:1523-1530.

Brizard, J. P., Carapito, C., Delalande, F., Van Dorsselaer, A., and Brugidou, C. 2006. Proteome analysis of plant-virus interactome: Comprehensive data for virus multiplication inside their hosts. Mol. Cell. Proteomics 5: 2279-2297.

Calderwood, M. A., Venkatesan, K., Xing, L., Chase, M. R., Vazquez, A., Holthaus, A. M., Ewence, A. E., Li, N., Hirozane-Kishikawa, T., Hill, D. E., Vidal, M., Kieff, E., and Johannsen, E. 2007. Epstein-Barr virus and virus human protein interaction maps. Proc. Natl. Acad. Sci. U.S.A. 104:7606-7611.

Caranta, C., M. A. Aranda, M. Tepfer, and J. J. Lopez-Moya, eds. 2011. Recent Advances in Plant Virology. Caister Academic Press, United Kingdom.

Casas-Mollano, J. A., Lao, N. T., and Kavanagh, T. A. 2006. Intronregulated expression of SUVH3, an Arabidopsis $\mathrm{Su}(\mathrm{var}) 3-9$ homologue. J. Exp. Bot. 57:3301-3311.

Chavez, J. D., Liu, N. L., and Bruce, J. E. 2011. Quantification of protein-protein interactions with chemical cross-linking and mass spectrometry. J. Proteome Res. 10:1528-1537.

Chavez, J. D., Cilia, M., Weisbrod, C. R., Ju, H. J., Eng, J. K., Gray, S. M. and Bruce, J. E. 2012. Cross-linking measurements of the Potato leafroll virus reveal protein interaction topologies required for virion stability, aphid transmission, and virus-plant interactions. J. Proteome Res. 11: 2968-2981.

Choi, H., Larsen, B., Lin, Z. Y., Breitkreutz, A., Mellacheruvu, D., Fermin, D., Qin, Z. S., Tyers, M., Gingras, A. C., and Nesvizhskii, A. I. 2011 SAINT: Probabilistic scoring of affinity purification-mass spectrometry data. Nat. Methods 8:70-73.

Choi, H., Liu, G., Mellacheruvu, D., Tyers, M., Gingras, A. C., and Nesvizhskii, A. I. 2012. Analyzing protein-protein interactions from affinity purification-mass spectrometry data with SAINT. Curr. Protoc. Bioinfor. 39:8.15.1-8.15.23.

Cilia, M., Peter, K. A., Bereman, M. S., Howe, K., Fish, T., Smith, D., Gildow, F., MacCoss, M. J., Thannhauser, T. W., and Gray, S. M. 2012 Discovery and targeted LC-MS/MS of purified polerovirus reveals differences in the virus-host interactome associated with altered aphid transmission. PLoS One 7:e48177.

Cilia, M., Johnson, R., Sweeney, M., DeBlasio, S. L., Bruce, J. E., MacCoss, M. J., and Gray, S. M. 2014. Evidence for lysine acetylation in the coat protein of a polerovirus. J. Gen. Virol. 95:2321-2327.

Conlon, F. L., Miteva, Y., Kaltenbrun, E., Waldron, L., Greco, T. M., and Cristea, I. M. 2012. Immunoisolation of protein complexes from Xenopus. Methods Mol. Biol. 917:369-390.

Cristea, I. M., and Chait, B. T. 2011. Affinity purification of protein complexes. Cold Spring Harb. Protoc. 2011(5):pdb.prot5611.

Cristea, I. M., Carroll, J. W., Rout, M. P., Rice, C. M., Chait, B. T., and MacDonald, M. R. 2006. Tracking and elucidating alphavirus-host protein interactions. J. Biol. Chem. 281:30269-30278.

Cristea, I. M., Moorman, N. J., Terhune, S. S., Cuevas, C. D., O'Keefe, E. S., Rout, M. P., Chait, B. T., and Shenk, T. 2010. Human cytomegalovirus pUL83 stimulates activity of the viral immediateearly promoter through its interaction with the cellular IFI16 protein. J. Virol. 84:7803-7814.

Cristea, I. M., Williams, R., Chait, B. T., and Rout, M. P. 2005. Fluorescent proteins as proteomic probes. Mol. Cell. Proteomics 4:1933-1941.

Culver, J. N., and Padmanabhan, M. S. 2007. Virus-induced disease: Altering host physiology one interaction at a time. Annu. Rev. Phytopathol. 45:221-243.

Davis, M. T., Spahr, C. S., McGinley, M. D., Robinson, J. H., Bures, E. J., Beierle, J., Mort, J., Yu, W., Luethy, R., and Patterson, S. D. 2001. Towards defining the urinary proteome using liquid chromatographytandem mass spectrometry. II. Limitations of complex mixture analyses. Proteomics 1:108-117.

de Chassey, B., Navratil, V., Tafforeau, L., Hiet, M. S., Aublin-Gex, A., Agaugué, S., Meiffren, G., Pradezynski, F., Faria, B. F., Chantier, T., Le Breton, M., Pellet, J., Davoust, N., Mangeot, P. E., Chaboud, A., Penin, F., Jacob, Y., Vidalain, P. O., Vidal, M., André, P., RabourdinCombe, C., and Lotteau, V. 2008. Hepatitis C virus infection protein network. Mol. Syst. Biol. 4:230.

DeLille, J. M., Sehnke, P. C., and Ferl, R. J. 2001. The Arabidopsis 14-3-3 family of signaling regulators. Plant Physiol. 126:35-38.

Di Carli, M., Benvenuto, E., and Donini, M. 2012. Recent insights into plant-virus interactions through proteomic analysis. J. Proteome Res. 11: 4765-4780.

Dodds, P. N., and Rathjen, J. P. 2010. Plant immunity: Towards an integrated view of plant-pathogen interactions. Nat. Rev. Genet. 11:539-548.

Dunker, A. K., Garner, E., Guilliot, S., Romero, P., Albrecht, K., Hart, J., Obradovic, Z., Kissinger, C., and Villafranca, J. E. 1998. Protein disorder and the evolution of molecular recognition: Theory, predictions and observations. Pac. Symp. Biocomput. 3:473-484.

Eigenbrode, S. D., Ding, H., Shiel, P., and Berger, P. H. 2002. Volatiles from potato plants infected with potato leafroll virus attract and arrest the virus vector, Myzus persicae (Homoptera: Aphididae). Proc. Biol. Sci. 269:455-460.

Elena, S. F., and Rodrigo, G. 2012. Towards an integrated molecular model of plant-virus interactions. Curr. Opin. Virol. 2:719-724.

Esau, K., and Hoefert, L. L. 1972. Ultrastructure of sugarbeet leaves infected with Beet western yellows virus. J. Ultrastruct. Res. 40:556-571.

Filichkin, S. A., Lister, R. M., McGrath, P. F., and Young, M. J. 1994. In vivo expression and mutational analysis of the Barley yellow dwarf virus readthrough gene. Virology 205:290-299.

Franceschini, A., Szklarczyk, D., Frankild, S., Kuhn, M., Simonovic, M., Roth, A., Lin, J., Minguez, P., Bork, P., von Mering, C., and Jensen, L. J. 2013. STRING v9.1: Protein-protein interaction networks, with increased coverage and integration. Nucleic Acids Res. 41:D808D815.

Garbutt, C. C., Bangalore, P. V., Kannar, P., and Mukhtar, M. S. 2014. Getting to the edge: Protein dynamical networks as a new frontier in plant-microbe interactions. Front. Plant Sci. 5:312. 
Golinowski, W., Tomenius, K., and Oxelfelt, P. 1987. Ultrastructural studies on potato phloem cells infected with Potato leafroll virus-comparison of two potato varieties. Acta. Agric. Scand. 37:3-19.

Grangeon, R., Jiang, J., and Laliberté, J. F. 2012. Host endomembrane recruitment for plant RNA virus replication. Curr. Opin. Virol. 2:683-690.

Gray, S., and Gildow, F. E. 2003. Luteovirus-aphid interactions. Annu. Rev. Phytopathol. 41:539-566.

Gray, S., Cilia, M., and Ghanim, M. 2014. Circulative, "nonpropagative" virus transmission: An orchestra of virus-, insect-, and plant-derived instruments. Adv. Virus Res. 89:141-199.

Ivanov, K. I., and Mäkinen, K. 2012. Coat proteins, host factors and plant viral replication. Curr. Opin. Virol. 2:712-718.

Ivanov, K. I., Puustinen, P., Gabrenaite, R., Vihinen, H., Rönnstrand, L., Valmu, L., Kalkkinen, N., and Mäkinen, K. 2003. Phosphorylation of the potyvirus capsid protein by protein kinase CK2 and its relevance for virus infection. Plant Cell 15:2124-2139.

Jiménez-Martínez, E. S., Bosque-Pérez, S. A., Berger, P. H., Zemetrad, R. S., Ding, H., and Eigenbrode, S. D. 2004. Volatile cues influence the response of Rhopalosiphum padi (Homoptera: Aphididae) to Barley yellow dwarf virus-infected transgenic and untransformed Wheat. Environ. Entomol. 33:1207-1216.

Jones, J. D., and Dangl, J. L. 2006. The plant immune system. Nature 444: 323-329.

Käll, L., Canterbury, J. D., Weston, J., Noble, W. S., and MacCoss, M. J. 2007. Semi-supervised learning for peptide identification from shotgun proteomics datasets. Nat. Methods 4:923-925.

Kanehisa, M., and Goto, H. 2000. KEGG: Kyoto Encyclopedia of Genes and Genomes. Nucleic Acids Res. 28:27-30.

Kanehisa, M., Goto, S., Sato, Y., Kawashima, M., Furumichi, M., and Tanabe, M. 2014. Data, information, knowledge and principle: Back to metabolism in KEGG. Nucleic Acids Res. 42:D199-D205.

Kaplan, I. B., Lee, L., Ripoll, D. R., Palukaitis, P., Gildow, F., and Gray, S. M. 2007. Point mutations in the potato leafroll virus major capsid protein alter virion stability and aphid transmission. J. Gen. Virol. 88:1821-1830.

Kessner, D., Chambers, M., Burke, R., Agus, D., and Mallick, P. 2008. ProteoWizard: Open source software for rapid proteomics tools development. Bioinformatics 24:2534-2536.

Koskinen, V. R., Emery, P. A., Creasy, D. M., and Cottrell, J. S. 2011. Hierarchical clustering of shotgun proteomics data. Mol. Cell. Proteomics 10:M110003822.

Lee, L., Kaplan, I. B., Ripoll, D. R., Liang, D., Palukaitis, P., and Gray, S. M. 2005. A surface loop of the Potato leafroll virus coat protein is involved in virion assembly, systemic movement, and aphid transmission. J. Virol. 79:1207-1214.

Liu, C., and Nelson, R. S. 2013. The cell biology of Tobacco mosaic virus replication and movement. Front. Plant Sci. 4:12.

Marks, C. E., Newbigin, E., and Ladiges, P. Y. 2011. Comparative morphology and phylogeny of Nicotiana section Suaveolentes (Solanaceae) in Australia and the South Pacific. Aust. Syst. Bot. 24:61-86.

Matzke, M. A., and Mosher, R. A. 2014. RNA-directed DNA methylation: An epigenetic pathway of increasing complexity. Nat. Rev. Genet. 15:394-408.

Mauck, K. E., De Moraes, C. M., and Mescher, M. C. 2010. Deceptive chemical signals induced by a plant virus attract insect vectors to inferior hosts. Proc. Natl. Acad. Sci. U.S.A. 107:3600-3605

Maule, A., Leh, V., and Lederer, C. 2002. The dialogue between viruses and hosts in compatible interactions. Curr. Opin. Plant Biol. 5:279-284.

Mellacheruvu, D., Wright, Z., Couzens, A. L., Lambert, J. P., St-Denis, N. A., Li, T., Miteva, Y. V., Hauri, S., Sardiu, M. E., Low, T. Y., Halim, V. A., Bagshaw, R. D., Hubner, N. C., Al-Hakim, A., Bouchard, A., Faubert, D., Fermin, D., Dunham, W. H., Goudreault, M., Lin, Z. Y., Badillo, B. G., Pawson, T., Durocher, D., Coulombe, B., Aebersold, R., Superti-Furga, G., Colinge, J., Heck, A. J., Choi, H., Gstaiger, M., Mohammed, S., Cristea, I. M., Bennett, K. L., Washburn, M. P., Raught, B., Ewing, R. M., Gingras, A. C., and Nesvizhskii, A. I. 2013. The CRAPome: A contaminant repository for affinity purification-mass spectrometry data. Nat. Methods 10:730-736.

Miteva, Y. V., Budayeva, H. G., and Cristea, I. M. 2013. Proteomics-based methods for discovery, quantification, and validation of protein-protein interactions. Anal. Chem. 85:749-768.

Moon, S., Han, D., Kim, Y., Jin, J., Ho, W. K., and Kim, Y. 2014. Interactome analysis of AMP-activated protein kinase (AMPK)- $\alpha 1$ and $-\beta 1$ in INS-1 pancreatic beta-cells by affinity purification-mass spectrometry. Sci. Rep. 4:4376.

Mukhtar, M. S., Carvunis, A. R., Dreze, M., Epple, P., Steinbrenner, J., Moore, J., Tasan, M., Galli, M., Hao, T., Nishimura, M. T., Pevzner, S. J., Donovan, S. E., Ghamsari, L., Santhanam, B., Romero, V., Poulin, M. M., Gebreab, F., Gutierrez, B. J., Tam, S., Monachello, D., Boxem, M., Harbort, C. J., McDonald, N., Gai, L., Chen, H., He, Y., Vandenhaute, J., Roth, F. P., Hill, D. E., Ecker, J. R., Vidal, M., Beynon, J., Braun, P., and
Dangl, J. L.; European Union Effectoromics Consortium. 2011. Independently evolved virulence effectors converge onto hubs in a plant immune system network. Science 333:596-601.

Nagy, P. D. 2008. Yeast as a model host to explore plant virus-host interactions. Annu. Rev. Phytopathol. 46:217-242.

Nesvizhskii, A. I., Keller, A., Kolker, E., and Aebersold, R. 2003. A statistical model for identifying proteins by tandem mass spectrometry. Anal. Chem. 75:4646-4658.

Nishi, H., Fong, J. H., Chang, C., Teichmann, S. A., and Panchenko, A. R. 2013. Regulation of protein-protein binding by coupling between phosphorylation and intrinsic disorder: Analysis of human protein complexes. Mol. Biosyst. 9:1620-1626.

Oh, C. S., and Martin, G. B. 2011. Tomato 14-3-3 protein TFT7 interacts with a MAP kinase kinase to regulate immunity-associated programmed cell death mediated by diverse disease resistance proteins. J. Biol. Chem. 286:14129-14136.

Öhman, T., Söderholm, S., Hintsanen, P., Välimäki, E., Lietzén, N., MacKintosh, C., Aittokallio, T., Matikainen, S., and Nyman, T. A. 2014. Phosphoproteomics combined with quantitative 14-3-3-affinity capture identifies SIRT1 and RAI as novel regulators of cytosolic doublestranded RNA recognition pathway. Mol. Cell. Proteomics 13: 2604-2617.

Opalka, N., Brugidou, C., Bonneau, C., Nicole, M., Beachy, R. N., Yeager, M., and Fauquet, C. 1998. Movement of rice yellow mottle virus between xylem cells through pit membranes. Proc. Natl. Acad. Sci. U.S.A. 95: 3323-3328.

Pallas, V., and García, J. A. 2011. How do plant viruses induce disease? Interactions and interference with host components. J. Gen. Virol. 92: 2691-2705.

Patarroyo, C., Laliberté, J. F., and Zheng, H. 2012. Hijack it, change it: how do plant viruses utilize the host secretory pathway for efficient viral replication and spread? Front. Plant Sci. 3:308.

Perkins, D. N., Pappin, D. J., Creasy, D. M., and Cottrell, J. S. 1999. Probability-based protein identification by searching sequence databases using mass spectrometry data. Electrophoresis 20:3551-3567.

Perry, K. L., Miller, J., Lister, R. M., and Mayo, M. A. 1998. Luteovirus isolation and RNA extraction. Methods Mol. Biol. 81:231-239.

Peter, K. A., Liang, D., Palukaitis, P., and Gray, S. M. 2008. Small deletions in the potato leafroll virus readthrough protein affect particle morphology, aphid transmission, virus movement and accumulation. J. Gen. Virol. 89:2037-2045.

Peter, K. A., Gildow, F., Palukaitis, P., and Gray, S. M. 2009. The C terminus of the polerovirus $\mathrm{p} 5$ readthrough domain limits virus infection to the phloem. J. Virol. 83:5419-5429.

Pinheiro, P., Bereman, M. S., Burd, J., Pals, M., Armstrong, S., Howe, K. J., Thannhauser, T. W., MacCoss, M. J., Gray, S. M., and Cilia, M. 2014. Evidence of the biochemical basis of host virulence in the greenbug aphid, Schizaphis graminum (Homoptera: Aphididae). J. Proteome Res. 13:2094-2108.

The Potato Genome Sequencing Consortium, Xu, X., Pan, S., Cheng, S., Zhang, B., Mu, D., Ni, P., Zhang, G., Yang, S., Li, R., Wang, J., Orjeda, G., Guzman, F., Torres, M., Lozano, R., Ponce, O., Martinez, D., De la Cruz, G., Chakrabarti, S. K., Patil, V. U., Skryabin, K. G., Kuznetsov, B. B., Ravin, N. V., Kolganova, T. V., Beletsky, A. V., Mardanov, A. V., Di Genova, A., Bolser, D. M., Martin, D. M., Li, G., Yang, Y., Kuang, H., Hu, Q., Xiong, X., Bishop, G. J., Sagredo, B., Mejía, N., Zagorski, W., Gromadka, R., Gawor, J., Szczesny, P., Huang, S., Zhang, Z., Liang, C., He, J., Li, Y., He, Y., Xu, J., Zhang, Y., Xie, B., Du, Y., Qu, D., Bonierbale, M., Ghislain, M., Herrera, Mdel. R., Giuliano, G., Pietrella, M., Perrotta, G., Facella, P., O'Brien, K., Feingold, S. E., Barreiro, L. E., Massa, G. A., Diambra, L., Whitty, B. R., Vaillancourt, B., Lin, H., Massa, A. N., Geoffroy, M., Lundback, S., DellaPenna, D., Buell, C. R., Sharma, S. K., Marshall, D. F., Waugh, R., Bryan, G. J., Destefanis, M., Nagy, I., Milbourne, D., Thomson, S. J., Fiers, M., Jacobs, J. M., Nielsen, K. L., Sønderkær, M., Iovene, M., Torres, G. A., Jiang, J., Veilleux, R. E., Bachem, C. W., de Boer, J., Borm, T., Kloosterman, B., van Eck, H., Datema, E., te Lintel Hekkert, B., Goverse, A., van Ham, R. C., Visser, R. G., and Visser, R. G. 2011. Genome sequence and analysis of the tuber crop potato. Nature 475:189-195.

Power, A. G., and Flecker, A. S. 2003. Virus specificity in disease systems: Are species redundant? Pages 330-334 in: The Importance of Species: Perspectives on Expendability and Triage. P. Kareiva and S. A. Levin, eds. Princeton University Press, Princeton, NJ, U.S.A.

Pumplin, N., and Voinnet, O. 2013. RNA silencing suppression by plant pathogens: Defence, counter-defence and counter-counter-defence. Nat. Rev. Microbiol. 11:745-760.

Reference Genome Group of the Gene Ontology Consortium, Gaudet, P., Chisholm, R., Berardini, T., Dimmer, E., Engel, S. R., Fey, P., Hill, D. P., 
Howe, D., Hu, J. C., Huntley, R., Khodiyar, V. K., Kishore, R., Li, D., Lovering, R. C., McCarthy, F., Ni, L., Petri, V., Siegele, D. A., Tweedie, S., Van Auken, K., Wood, V., Basu, S., Carbon, S., Dolan, M., Mungall, C. J., Dolinski, K., Thomas, P., Ashburner, M., Blake, J. A., Cherry, J. M., Lewis, S. E., Balakrishnan, R., Christie, K. R., Costanzo, M. C., Deegan, J., Diehl, A. D., Drabkin, H., Fisk, D. G., Harris, M., Hirschman, J. E., Hong, E. L., Ireland, A., Lomax, J., Nash, R. S., Park, J., Sitnikov, D., Skrzypek, M. S., Apweiler, R., Bult, C., Eppig, J., Jacob, H., Parkhill, J., Rhee, S., Ringwald, M., Sternberg, P., Talmud, P., Twigger, S., and Westerfield, M. 2009. The Gene Ontology's Reference Genome Project: A unified framework for functional annotation across species. PLoS Comput. Biol. 5:e1000431.

Ribet, D., and Cossart, P. 2010. Pathogen-mediated posttranslational modifications: A re-emerging field. Cell 143:694-702.

Riechmann, J. L., Laín, S., and García, J. A. 1992. Highlights and prospects of potyvirus molecular biology. J. Gen. Virol. 73:1-16.

Rocha, P. S., Sheikh, M., Melchiorre, R., Fagard, M., Boutet, S., Loach, R., Moffatt, B., Wagner, C., Vaucheret, H., and Furner, I. 2005. The Arabidopsis HOMOLOGY-DEPENDENT GENE SILENCING1 gene codes for an S-adenosyl-L-homocysteine hydrolase required for DNA methylation-dependent gene silencing. Plant Cell 17:404-417.

Rodrigo, G., Carrera, J., Ruiz-Ferrer, V., del Toro, F. J., Llave, C., Voinnet, O., and Elena, S. F. 2012. A meta-analysis reveals the commonalities and differences in Arabidopsis thaliana response to different viral pathogens. PLoS One 7:e40526.

Schneider, C. A., Rasband, W. S., and Eliceiri, K. W. 2012. NIH Image to ImageJ: 25 years of image analysis. Nat. Methods 9:671-675.

Schoelz, J. E., Harries, P. A., and Nelson, R. S. 2011. Intracellular transport of plant viruses: Finding the door out of the cell. Mol. Plant 4:813-831.

Shepardson, S., Esau, K., and McCrum, R. 1980. Ultrastructure of potato leaf phloem infected with potato leafroll virus. Virology 105:379-392.

Skarra, D. V., Goudreault, M., Choi, H., Mullin, M., Nesvizhskii, A. I., Gingras, A. C., and Honkanen, R. E. 2011. Label-free quantitative proteomics and SAINT analysis enable interactome mapping for the human Ser/Thr protein phosphatase 5. Proteomics 11:1508-1516.

Smith-Kinnaman, W. R., Berna, M. J., Hunter, G. O., True, J. D., Hsu, P., Cabello, G. I., Fox, M. J., Varani, G., and Mosley, A. L. 2014. The interactome of the atypical phosphatase Rtr1 in Saccharomyces cerevisiae. Mol. Biosyst. 10:1730-1741.

Smoot, M. E., Ono, K., Ruscheinski, J., Wang, P. L., and Ideker, T. 2011. Cytoscape 2.8: New features for data integration and network visualization. Bioinformatics 27:431-432.

Spahr, C. S., Davis, M. T., McGinley, M. D., Robinson, J. H., Bures, E. J., Beierle, J., Mort, J., Courchesne, P. L., Chen, K., Wahl, R. C., Yu, W., Luethy, R., and Patterson, S. D. 2001. Towards defining the urinary proteome using liquid chromatography-tandem mass spectrometry. I. Profiling an unfractionated tryptic digest. Proteomics 1:93-107.

Stewart, L. R., Ding, B., and Falk, B. W. 2013. Viroids and phloem-limited viruses: Unique molecular probes of phloem biology. In: Phloem: Molecular Cell Biology, Systemic Communication, Biotic Interactions. G. A. Thompson and A. J. E. van Bel, eds. Wiley-Blackwell, Hoboken, NJ, U.S.A.

Szklarczyk, D., Franceschini, A., Kuhn, M., Simonovic, M., Roth, A., Minguez, P., Doerks, T., Stark, M., Muller, J., Bork, P., Jensen, L. J., and von Mering, C. 2011. The STRING database in 2011: Functional interaction networks of proteins, globally integrated and scored. Nucleic Acids Res. 39:D561-D568.

Tanz, S. K., Castleden, I., Hooper, C. M., Vacher, M., Small, I., and Millar, H. A. 2013. SUBA3: A database for integrating experimentation and prediction to define the SUBcellular location of proteins in Arabidopsis. Nucleic Acids Res. 41:D1185-D1191.

Torrance, L. 1992. Analysis of epitopes on potato leafroll virus capsid protein. Virology 191:485-489.

Uhart, M., and Bustos, D. M. 2014. Protein intrinsic disorder and network connectivity. The case of 14-3-3 proteins. Front. Genet. 5:10.

UniProt Consortium. 2014. Activities at the Universal Protein Resource (UniProt). Nucleic Acids Res. 42:D191-D198.

Wang, J. Y., Chay, C., Gildow, F. E., and Gray, S. M. 1995. Readthrough protein associated with virions of barley yellow dwarf luteovirus and its potential role in regulating the efficiency of aphid transmission. Virology 206:954-962.

Whitham, S. A., Yang, C., and Goodin, M. M. 2006. Global impact: Elucidating plant responses to viral infection. Mol. Plant-Microbe Interact. 19:1207-1215.

Wu, K., Tian, L., Malik, K., Brown, D., and Miki, B. 2000. Functional analysis of HD2 histone deacetylase homologues in Arabidopsis thaliana. Plant J. 22:19-27.

Zaccomer, B., Haenni, A. L., and Macaya, G. 1995. The remarkable variety of plant RNA virus genomes. J. Gen. Virol. 76:231-247.

\section{AUTHOR-RECOMMENDED INTERNET RESOURCES}

Chorus webserver: chorusproject.org/pages/index.html

Crapome webserver: crapome.org/

ImageJ64: imagej.nih.gov/ij

$N$. benthamiana in-house database: bti.cornell.edu/nicotiana-benthamiana/ Protein Prospector (P. R. Baker and K. R. Clauser): prospector.ucsf.edu SAINT webserver: www.crapome.org

STRING database: string-db.org/ 